\title{
WestVirginiaUniversity
}

THE RESEARCH REPOSITORY @ WVU

Graduate Theses, Dissertations, and Problem Reports

2016

\section{Motive Taxonomic and Sex Considerations of Murder-Suicide}

Matthew R. McNally

Follow this and additional works at: https://researchrepository.wvu.edu/etd

\section{Recommended Citation}

McNally, Matthew R., "Motive Taxonomic and Sex Considerations of Murder-Suicide" (2016). Graduate Theses, Dissertations, and Problem Reports. 6204.

https://researchrepository.wvu.edu/etd/6204

This Dissertation is protected by copyright and/or related rights. It has been brought to you by the The Research Repository @ WVU with permission from the rights-holder(s). You are free to use this Dissertation in any way that is permitted by the copyright and related rights legislation that applies to your use. For other uses you must obtain permission from the rights-holder(s) directly, unless additional rights are indicated by a Creative Commons license in the record and/ or on the work itself. This Dissertation has been accepted for inclusion in WVU Graduate Theses, Dissertations, and Problem Reports collection by an authorized administrator of The Research Repository @ WVU.

For more information, please contact researchrepository@mail.wvu.edu. 
Motive Taxonomic and Sex Considerations of Murder-Suicide

Matthew R. McNally

Dissertation submitted

to the Eberly College of Arts and Sciences

at West Virginia University

In partial fulfillment of the requirements for the degree of

Doctor of Philosophy in

Clinical Psychology

\author{
William Fremouw, Ph.D., Chair \\ Amy Fiske, Ph.D. \\ Aaron Metzger, Ph.D. \\ Melissa Blank, Ph.D. \\ Nicholas Bowman, Ph.D. \\ Department of Psychology
}

Morgantown, West Virginia

2016

Keywords: murder-suicide, female perpetrator, suicide, motive, taxonomy

Copyright 2016 Matthew R. McNally 


\section{ABSTRACT \\ Motive Taxonomic and Sex Considerations of Murder-Suicide}

\section{Matthew R. McNally}

Using data obtained from the Centers for Disease Control and Prevention's (CDC) National Violent Death Reporting System (NVDRS), the present study examines two emerging topics in the field of murder-suicide research. The majority of murder-suicide perpetrators are male, so female perpetrators are rarely studied. First, the current study uses the largest known sample of female murder-suicide perpetrators to explore murder-suicide differences by sex. Second, motives from the recently-proposed perversion of virtue theory of murder-suicide are operationalized with input from the theory developer and analyzed. The perversion of virtue theory is compared to the predominant murder-suicide motive typology to evaluate whether it classifies murder-suicide incidents in a novel and meaningful manner. Variables relating to the perpetrators, victims, mental health, substance use, and weapon type are explored, with an emphasis on variables that are amenable to intervention. Conclusions regarding female perpetrators, the perversion of virtue motives, and murder-suicide detection and prevention strategies are discussed along with future directions for research in the field of murder-suicide. 


\section{TABLE OF CONTENTS}

Motive Taxonomic and Sex Considerations of Murder-Suicide .............................................. 1

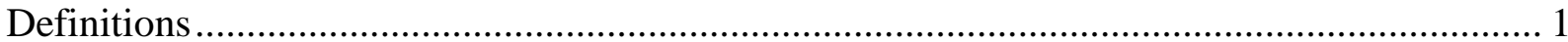

Perpetrator Demographic Information .................................................................... 3

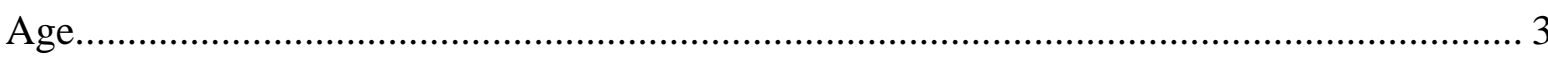

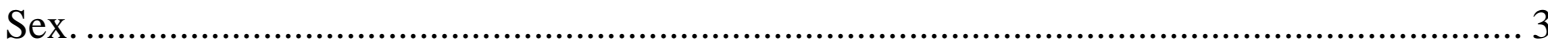

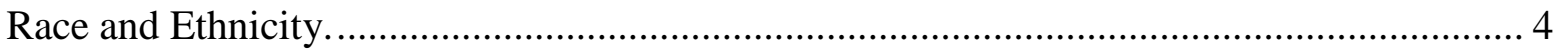

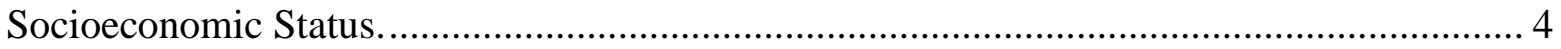

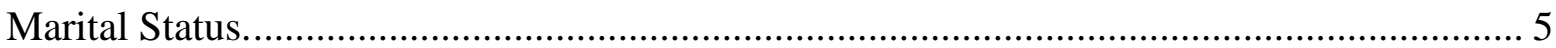

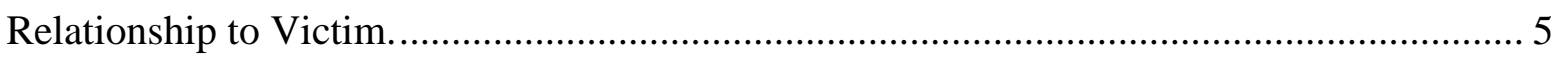

Other Variables of Interest ........................................................................................ 6

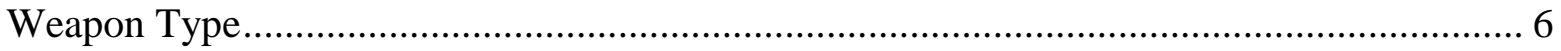

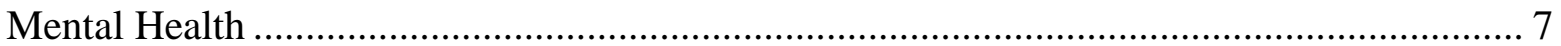

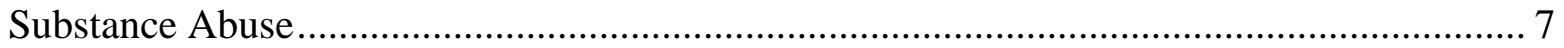

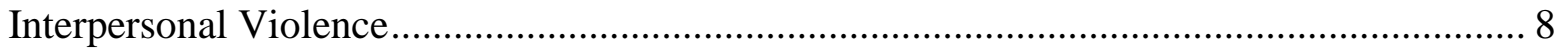

Murder-suicide as a Subset of Murder or Suicide............................................................. 8

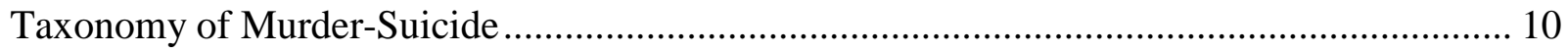

Marzuk, Tardiff, and Hirsch (MTH) typology ........................................................... 10

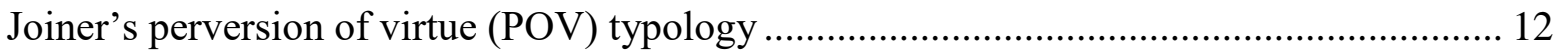

How is Murder-Suicide Studied? .............................................................................. 14

Emerging Topics in the Study of Murder-Suicide .......................................................... 16

Female-Perpetrated Murder-Suicide .................................................................... 16

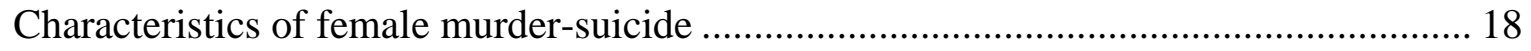

Joiner's Perversion of Virtue (POV) Theory ............................................................ 19

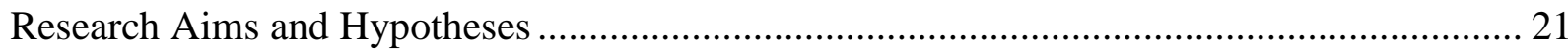

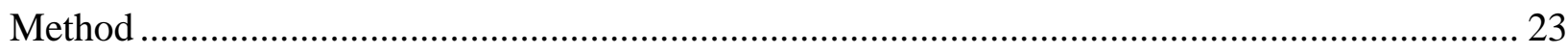

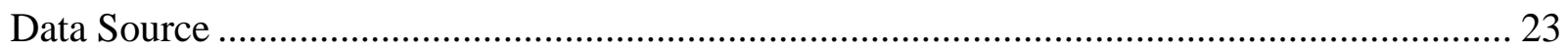

Data Access, Case Finding, and Estimated Sample Size .................................................... 24

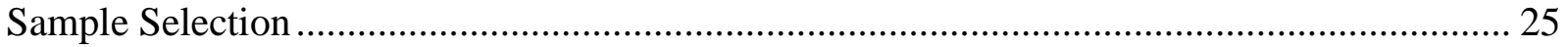

Data Coding Procedures for Murder-Suicide Motives........................................................ 27

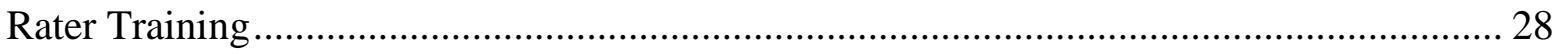

Rater Coding and Procedures for Combining Raters' Codes ......................................... 28 


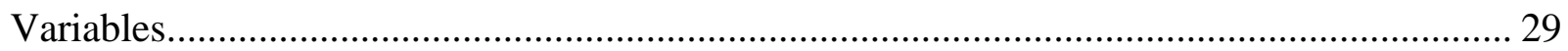

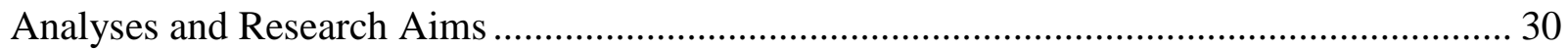

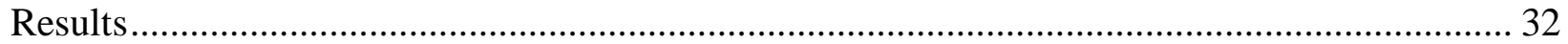

Comparing Sex of Murder-Suicide Perpetrators ................................................................. 32

Comparing Murder-Suicide Motive Typologies ………………………….......................... 33

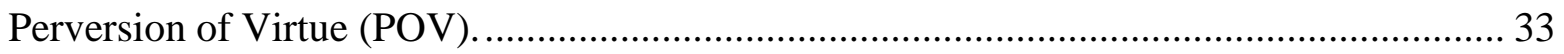

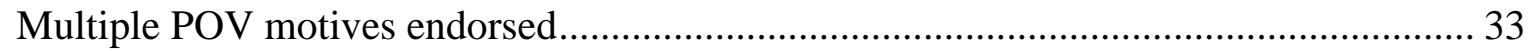

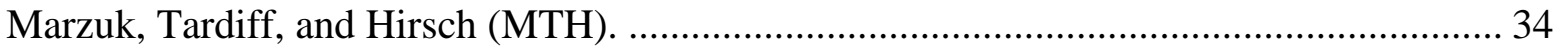

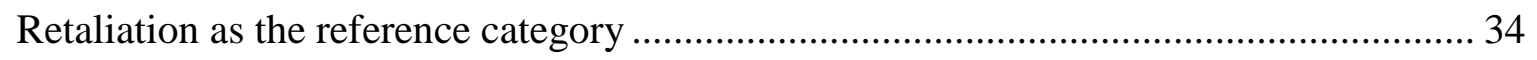

Altruistic/Extended Suicide as the reference category ................................................... 35

Multiple MTH motives endorsed................................................................................ 36

POV and MTH Primary Motive Overlap ………………................................................. 37

Comparing Suicide Decedents and Murder-Suicide Perpetrators............................................. 37

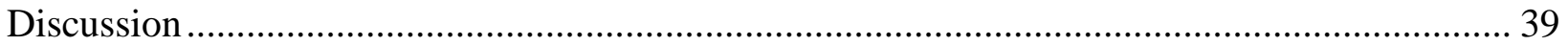

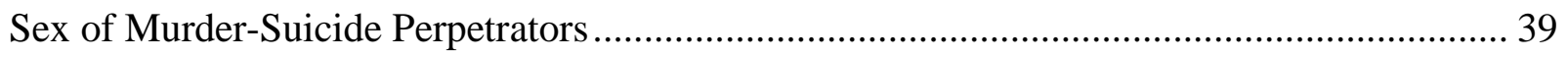

Testing Elements of the Perversion of Virtue Theory (POV) of Murder-Suicide ..................... 41

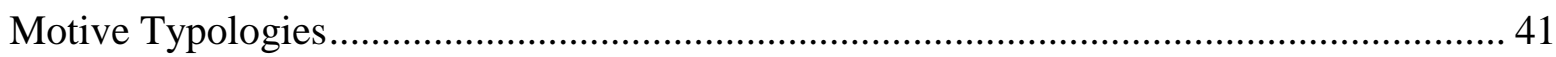

Murder-suicide as a subtype of suicide ………………..................................................... 45

Implications for Public Policy and Clinical Practice Interventions .......................................... 47

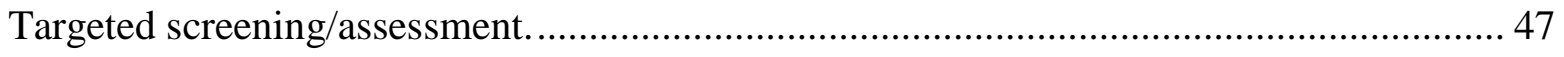

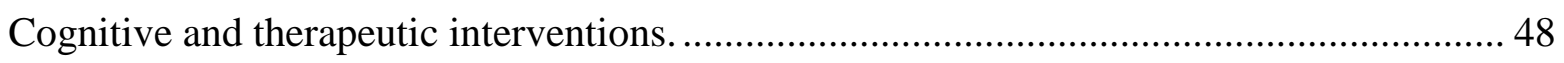

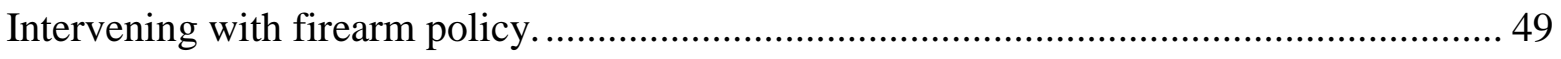

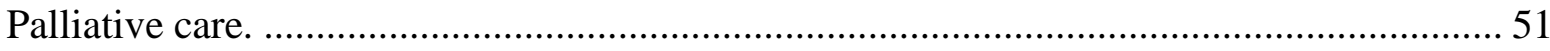

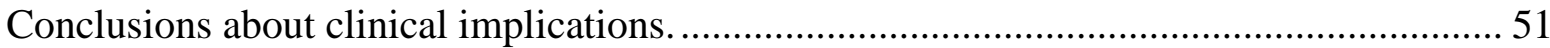

Limitations and Future Research Directions ..................................................................... 52

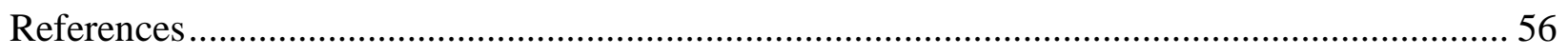

Table 1: Interrater Reliability of Murder-Suicide Motive Codes ................................................. 64

Table 2: Demographic Data for Male and Female Murder-Suicide Perpetrators ........................... 65

Table 3: Logistic Regression Predicting Murder-Suicide Perpetrator Sex ..................................... 66

Table 4: Demographic Data for Perversion of Virtue Murder-Suicide Motives ........................... 67

Table 5: Logistic Regression Predicting Murder-Suicide Perpetrator Sex .................................... 68

Table 6: Demographic Data for Marzuk, Tardiff, and Hirsch Murder-Suicide Motives............... 69 
Table 7: Multinomial Logistic Regression with MTH Retaliation as Reference Category......... 70

Table 8: Multinomial Logistic Regression with MTH Altruistic/Extended Suicide as Reference

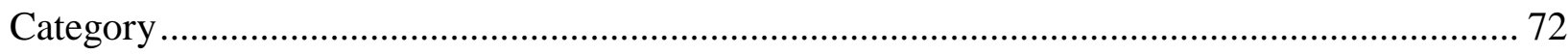

Table 9: Crosstabulation of MTH and POV Motive Codes.................................................. 74

Table 10: Demographic Data and Logistic Regression Predicting Murder and Murder-Suicide. 75

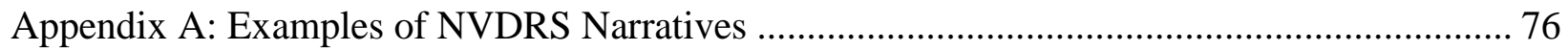

Appendix B: Perversion of Virtue Motive Coding Definitions ................................................. 77

Appendix C: Marzuk, Tardiff, and Hirsch Motive Coding Definitions ..................................... 86

Appendix D: Coding Rules for Merging Three Raters’ Motive Codes ................................... 97 
Motive Taxonomic and Sex Considerations of Murder-Suicide

The headlines appear in the media each week. "Veterinarian Victim of Murder-Suicide," "Two Dead in... Apparent Murder-Suicide," and "Family of Four Shot Dead in Father's Day Murder Suicide" are merely a sampling of articles about murder-suicide incidents that happened in June and July 2015 (Associated Press, 2015; Hongoltz-Hetling, 2015; Meyers, 2015). Annually, at least 1,000 to 1,500 people die in murder-suicides in the United States (Violence Policy Center, 2012). Murder-suicides are estimated to occur at rates of $0.1-0.3$ per 100,000 persons in the United States (Eliason, 2009; Large et al., 2009; Liem, Barber, Markwalder, Killias, \& Nieuwbeerta, 2011). While murder-suicide incidents are relatively rare, at least two individuals are fatally affected by each incident before factoring in any impact the family, community, police, and medical personnel might incur from their exposure to these types of events.

Murder-suicides are not studied as frequently as homicides or suicides. Nevertheless, prior research has established a firm foundation of general findings regarding murder-suicide. Still, despite general acceptance of certain elements of murder-suicide research, debates about fundamental topics persist (e.g., a unified operational definition). In the following sections we describe what is known about murder-suicide and highlight the major points of debate, before introducing emerging topics and the current study.

\section{Definitions}

Most generally, murder-suicide perpetrators are those who intentionally kill one or more other persons prior to enacting their own death by suicide. Marzuk, Tardiff, and Hirsch (1992) describe murder-suicide as "a two-stage sequential act" in which a person commits a murder followed by a suicide "within one week" (p. 3179, 3182). Definitions of murder-suicide tend to include some reference to the sequential connection between murder and suicide; however, there 
has been great disparity in descriptions of what constitutes an acceptable timeframe between the murder and the suicide. Marzuk and colleagues (1992) recommended that the suicide occur within one week of the murder(s), while others have used timeframes as short as 24 hours and as long as three months (Allen, 1983; Bossarte, Simon, \& Barker, 2006). Part of the disagreement over this timeframe has to do with viewing the suicide in murder-suicide incidents as not the result of remorse after a murder, but as part of a previously planned "unified two-stage sequential act" (Marzuk et al., 1992, p. 3181-2).

Timeframes are often used to easily identify motivationally linked murders and suicides. In some samples, timeframes are imposed on the data by the collecting agency. Such is the case with the Centers for Disease Control and Prevention's (CDC) National Violent Death Reporting System (NVDRS) data, which links murders and suicides that occur within 24 hours (one calendar day) of one another (Bossarte et al., 2006). Joiner (2014) has advocated for the removal of timeframes altogether, instead placing the onus for determining a "genuine murder-suicide" on "continuity of process," such that any timeframe is feasible so long as the perpetrator premeditated the murder(s) and eventual suicide prior to taking either action (p. 13-15, 39). Still, it is likely that this disagreement over timeframe is only relevant in a limited number of cases. Comstock et al. (2005) found only one of their sample of 73 murder-suicide incidents had a suicide occur more than 24 hours after the associated murder. While the suicide portion of a premeditated murder-suicide incident may occur at any time after the murder, suicide in murdersuicide incidents primarily happens in the minutes or hours that follow the murder (Joiner, 2014; Marzuk et al., 1992). To summarize, murder-suicides are premeditated two-stage sequential acts in which a perpetrator intentionally acts in a manner that results in the death by murder of one or 
more individuals followed by an intentional act that leads to death by suicide. Usually, the acts leading to murder and suicide are closely temporally related.

In the following sections, important variables relating to the study of murder-suicide perpetration are reviewed along with some of the predominant conceptual and methodological questions.

\section{Perpetrator Demographic Information}

Age. Logan and colleagues (2008) found approximately two thirds of their representative sample of murder-suicide perpetrators from 17 states fell into the 20-49 years age range, while the remaining third was 50 years of age or older. Less than three percent of perpetrators were younger than 19 years of age, and the median age of perpetrators was 43 years (Logan et al., 2008). Mean and median ages of samples of murder-suicide perpetrators are routinely found to be between 40 and 50 years of age (Bossarte et al., 2006; De Koning \& Piette, 2014; Eliason 2009; Logan et al., 2008; Milroy, 1998; Yip, Wong, Cheung, Chan, \& Beh, 2009). Studies that examine subsamples of murder-suicide perpetrators, such as those who kill children or ailing spouses, will likely observe slightly younger or older respective mean perpetrator ages. Overall, perpetrator ages range from teenage through older adulthood (Eliason, 2009; Liem \& Nieuwbeerta, 2010).

Sex. Males have been found to be the perpetrators in approximately $90 \%$ of murdersuicide incidents in studies from the United States, Australia, Ghana, and European nations, while females make up the majority of victims in such incidents (Adinkrah, 2014; Bossarte et al., 2006; Carcach \& Grabosky, 1998; Liem, 2011; Logan et al., 2008; Marzuk et al., 1992). A trio of studies from Fiji, Hong Kong, and Japan have obtained samples in which the sex of murdersuicide perpetrators is more balanced, with some even reporting a slight majority of female 
perpetrators (Adinkrah, 2003; Sakuta, 1995; Yip et al., 2009). While the Adinkrah (2003) and Sakuta (1995) studies show a majority of female perpetrators, both have sample sizes of less than 30 incidents. The Yip and colleagues (2009) study obtained a more substantive sample size $(\mathrm{N}=$ 99), and found males to perpetrate approximately $70 \%$ of the murder-suicide incidents in Hong Kong. Because of this vast sex disparity across different studies and countries, much of what is known about murder-suicide perpetrators is what is known about male murder-suicide perpetrators. The largest identified studies that include female murder-suicide perpetrators and report variables by sex all have obtained sample sizes of less than 40 (Fishbain, Rao, \& Aldrich, 1985; Logan et al., 2008; Logan, Walsh, Patel, \& Hall, 2013; Yip et al., 2011).

Race and Ethnicity. With regard to racial and ethnic demographic characteristics, the majority of murder-suicide perpetrators tend to be from the predominant racial and ethnic backgrounds of the countries in which the phenomenon was studied, and tend to kill those who are of the same racial and ethnic background (Carcach \& Grabosky, 1998; Chan, Beh, \& Broadhurst, 2003). In the United States, most murder-suicide perpetrators are of White/Caucasian and non-Hispanic race and ethnicity (Logan et al., 2008).

Socioeconomic Status. Socioeconomic status (SES) of murder-suicide perpetrators is frequently unknown or not reported in studies. Those studies that do report SES have drawn differing conclusions about murder-suicide perpetrators. In their literature review, Felthous and Hempel (1995) report that murder-suicide perpetrators in the United States tend to be employed individuals from the middle and upper classes. De Koning and Piette (2014) found that, though only a third of their Belgian sample's SES was known, perpetrators tended to be from low or middle socioeconomic classes. Adinkrah (2014) cited numerous examples of studies from the United States in which murder-suicide perpetrators are found to be predominantly of lower or 
middle, working/labor classes. Adinkrah (2014) himself found that most murder-suicide perpetrators in Ghana were of "low socioeconomic status" (p. 364).

Marital Status. Studies have consistently found that the majority of murder-suicide perpetrators have been or are currently married at the time of the offense (Logan et al., 2013; Saleva et al., 2007; Yip et al., 2009). Logan and colleagues (2008) found intimate partner conflicts to be a precipitating factor in $53.9 \%$ of their sample of 408 murder-suicide incidents. Given the catalytic role relationship dissolution plays in murder-suicide, it is unsurprising that a portion of perpetrators are divorced or separated at the time of the offense (Eliason, 2009; Hannah, Turf, \& Fierro, 1998; Logan et al., 2013).

Relationship to Victim. Eliason (2009) states, "Most murder-suicides are spousal/consortial, involving a man killing his wife, girlfriend, ex-wife, or ex-girlfriend” (p. 372). Bossarte and colleagues (2006) reported that $58 \%$ of victims were intimate partners of the perpetrator. Malphurs and Cohen (2002) found approximately $85 \%$ of the victims in their sample were family members or intimate partners. Similarly, Logan and colleagues (2008) found that only 42 of $408(10.3 \%)$ killed extrafamilial victims. Filicides, in which a parent kills a child, are the second most common form of murder-suicide (Liem, 2010; Malphurs \& Cohen, 2002; Stack, 1997). The terms infanticide and pedicide are also used to denote instances during which an infant or child is killed by someone other than a parent (e.g., grandparent, step-parent, intimate partner of parent). Following child victims, perpetrators are next most likely to kill other family members and are least likely to perpetrate murder-suicide against victims outside of the family (Liem, 2010; Logan et al., 2008; Malphurs \& Cohen, 2002). 


\section{Other Variables of Interest}

Weapon Type. In countries with a relatively high rates of civilian firearm ownership, firearms are the primary weapon used to enact murder-suicide. In the United States (88.1 guns per hundred persons [GPHP], first in the world), firearms are used in approximately $90 \%$ of murder-suicide incidents (Eliason, 2009; Karp, 2007; Violence Policy Center, 2012). Liem and Oberwittler (2012) found that while firearms were the primary weapon used in murder-suicides in most European countries, the rates of firearm use were lower than is typically reported in United States samples. Firearms were used in $79 \%$ of murder-suicide incidents in Switzerland (45.7 GPHP), 71\% in Finland (45.3 GPHP), 50\% in Germany (30.3 GPHP), 46\% in Spain (10.4 GPHP), 38\% in the Netherlands (3.9 GPHP), and 29\% in England and Wales (6.2 GPHP; Karp, 2007; Liem \& Oberwittler, 2012). Perpetrators in China (Hong Kong), Poland, and Fiji—which have relatively low guns per hundred persons rates of $4.9,1.3$, and 0.5 respectively-most frequently enact murder-suicide using other methods (Karp, 2007; Liem \& Oberwittler, 2012; McNally, Patton, \& Fremouw, 2015). In Hong Kong "knife chopping and carbon-monoxide poisoning" are the primary methods of enacting murder-suicide (Yip et al., 2009; p. 188). In Fiji “stabbing, hanging, and burning” were predominant methods (Adinkrah, 2003; p. 69). In Poland, stabbing or cutting (25\%) was found to be the primary method of completing murder-suicide (Liem \& Oberwittler, 2012).

Infrequently, researchers have recorded whether a perpetrator used different weapon types in the murder and suicide portions of murder-suicide incidents. Liem and Niuewbeerta (2010) reported frequency data on the methods used for the murder and the suicide components of murder-suicide incidents. The frequencies indicate that a small proportion of perpetrators do use different methods for murder and suicide in a murder-suicide incident. Similarly, Adinkrah 
(2003) observed that not all murder-suicide perpetrators chose to die in the same manner in which he or she had killed.

Mental Health. Logan and colleagues (2008) found 13.7\% of murder-suicide perpetrators were experiencing a mental health problem at the time of the incident. The rate was higher for female perpetrators $(42.9 \%)$ than for male perpetrators $(11.0 \%)$. The same study found that $38.4 \%$ of a separate sample of suicide decedents suffered from a mental health problem at the time of their suicide. Eliason (2009) reports that depression is the most common diagnosis among murder-suicide perpetrators, but that rates of depression varied widely (from 19\%-85\%) among samples. Twelve percent of the perpetrators in the Logan and colleagues (2008) study, $17.5 \%$ of those in the Cohen, Llorente, and Eisdorfer (1998) study, and 8.6\% of the perpetrators in the Bossarte, Simon, and Barker (2006) study were depressed at the time of the incident. Mental illness other than depression was present in $8.6 \%$ of the Cohen and colleagues (1998) sample. A history of suicide attempts was found in $4.4 \%$ of one sample of murder-suicide perpetrators (Cohen et al., 1998). Similarly, historical suicide attempts were found among 3.5\% of murder-suicide perpetrators in contrast to $17.4 \%$ of suicide decedents (Logan et al., 2008). Suicidal ideation among murder-suicide perpetrators ranged from $12.4 \%$ to $16.1 \%$ (Cohen et al., 1998; Logan et al., 2013).

Substance Abuse. Substance use, particularly alcohol use, is prevalent among a minority of murder-suicide perpetrators at the time of the offense (Eliason, 2009). Marzuk and colleagues (1992) reviewed studies and found that $12-50 \%$ of perpetrators "had alcohol detectable in their blood at autopsy" (p. 3182). Perpetrators of murder-suicide are more often found to be acutely intoxicated $(22.3 \%)$ than to have a history of alcohol or other substance abuse $(11.8 \%$; Logan et al., 2008). Suicide decedents are more likely to abuse drugs and alcohol and to be acutely 
intoxicated at the time of death than are murder-suicide perpetrators (Logan et al., 2008; Saleva et al., 2007).

Interpersonal Violence. In his review of murder-suicide studies, Eliason (2009) noted between nine and 54 percent of perpetrators of murder-suicides had histories of domestic violence perpetration. Of a sample of 67 males who killed women before completing suicide, 23.7\% had a prior arrest for domestic violence (Koziol-McClain et al., 2006). Manning (2015) reported $55 \%$ of murder-suicide perpetrators in his sample had a history of violence, typically directed toward intimate partners.

\section{Murder-suicide as a Subset of Murder or Suicide}

Another oft-questioned aspect of murder-suicide is whether the phenomenon is more like murder, more like suicide, or a unique type of fatal occurrence. Researchers have compared various characteristics of murders and/or suicides, and murder-suicides. In a study of murdersuicide perpetrators in England, Milroy (1998) described a number of commonalities between suicide and murder-suicide, but identified murder-suicide as "a distinct sub-category of homicide” (p. 63). Saleva, Putkonen, Kiviruusu, and Lönnqvist (2007) noted the similar rates of male perpetrators among male homicide and murder-suicide incidents, but also acknowledged the prevalence of depression in both suicide and murder-suicide. Saleva and collaborators (2007) ultimately concluded that "homicide-suicide incidents may be closer to the phenomenon of suicide than to homicide, but nevertheless seem to be a distinct phenomenon" (p. 207).

When Logan and colleagues (2008) compared murder-suicide perpetrators to murder perpetrators and suicide decedents, they found similar rates of male perpetrators among murdersuicide and murder incidents (approximately 90\%). Murder-suicide and suicide perpetrators both tended to be of White/non-Hispanic race and ethnicity. Male murder-suicide perpetrators were 
less likely than male suicide perpetrators to have histories of mental illness or substance abuse, but were more likely to have historical intimate partner conflicts. Female murder-suicide perpetrators resembled female suicide perpetrators on several variables including rates of depression, current or prior mental health treatment, and historical intimate partner conflict. Female murder-suicide perpetrators were less likely than female suicide decedents to have historical suicide attempts or to be intoxicated during the incident (Logan et al., 2008). In an epidemiological study, Large, Smith, and Neilssen (2009) found murder-suicide rates in the United States more closely track rates of homicide than suicide over time. Homicide by firearm was the variable found to account for "almost all of the variation" in the U.S. murder-suicide rate (p. 304). Murder-suicides from outside the United States were not significantly associated with changes in either homicide or suicide rates over time. In a study of cases from the Netherlands, Liem and Nieuwbeerta (2010) found murder-suicides were different from both murders and suicides on a number of "sociodemographic and event characteristics" (p. 133).

Salari and Sillito (2016) used content analysis of newspaper accounts of intimate partner murder-suicides to determine whether the incidents were primarily motivated by suicidal or homicidal intent. Overall, they found $48 \%$ of cases were motivated by homicidal intent compared to $27 \%$ motivated by suicidal intent. Intent was missing in $25 \%$ of cases. Of those cases with determined primary intent, homicidal intent was more prevalent among young (18-44 years; $80 \%$ primary homicidal intent) and middle-aged (44-59 years; $74 \%$ primary homicidal intent). Suicidal intent was primary among elder perpetrators (60+ years; 63\%;).

Others have conducted literature reviews and presented informed opinions on the issue. Marzuk et al. (1992) state that "murder-suicide occupies a distinct epidemiological domain that overlaps with suicide, domestic homicide, and mass murder" (p. 3179). In the literature review 
portion of Large and colleagues 2009 publication, the authors report that murder-suicide "has elements of both murder and suicide, although it is widely believed that [murder]-suicide has more in common with suicide than homicide" (p. 294). A 2013 systematic review and metaanalysis concluded that murder-suicides represent "a distinct entity, with characteristics distinguishing them both from homicides and suicides" (Panczak et al., p. 28). In summary, much of the recent literature recognizes murder-suicide as a phenomenon distinct from, but intimately related to, murder and suicide.

\section{Taxonomy of Murder-Suicide}

Over the past 80 years, numerous efforts have been made to group and classify murdersuicide incidents (Liem, 2010). Commonly, the classifications have focused on the relationship between the perpetrator and victim(s), the perpetrator's motive and precipitating factors, the demographic or psychological variables associated with the perpetrator, or some combination of the aforementioned variables.

Marzuk, Tardiff, and Hirsch (MTH) typology. The most frequently-cited typology of murder-suicide comes from Marzuk, Tardiff, and Hirsch (1992; Nock \& Marzuk, 1999)— henceforth referred to as MTH typology — in which incidents are coded by victim-perpetrator relationship and motive. The MTH typology groups victim-perpetrator relationship into three major categories: spousal or consortial, familial, or extrafamilial. Within each category are subcategories to specify the exact relationship between the victim(s) and perpetrators (e.g., spouse, consort, mother, father, child, other adult family member). The motive categories include: amorous jealousy, declining health/mercy killing, altruism/extended suicide, family financial/social stressors, retaliation, and other or unspecified motives. Each murder-suicide incident may be coded with multiple victim-perpetrator relationships and motives, resulting in 
numerous possible types of murder-suicides. The following paragraph describes the five most common types of murder-suicide espoused by Marzuk et al. (1992), based on their review of the extant literature:

Spousal amorous jealousy was identified as the predominant type of murder-suicide. It typically occurs when an adult male, motivated by real or perceived termination of a romantic relationship, kills his spouse/consort and occasionally her new romantic interest. Marzuk et al. (1992) estimate that between 50 and $75 \%$ of all murder-suicides are of this type, and $90 \%$ of this type are perpetrated by males. Spousal declining health types of murder-suicide characteristically involve elderly male perpetrators who kill their spouses when one or both of them has a serious physical illness. Filicide-suicides are murder-suicides in which a parent kills a child or children prior to enacting his or her own suicide. Mothers are the more common perpetrator in this type. They are often depressed and wish to save their dependent children from life's difficulties. Familicide-suicide incidents occur when a perpetrator (often male) kills his entire family prior to his own suicide. Such incidents are frequently driven by family social or financial stressors and the perpetrator's perceived altruistic deliverance of his family from such problems. Finally, extrafamilial murder-suicides tend to be intertwined with retaliatory motives as males typically enact revenge on an extrafamilial individual for some perceived wrong.

Following the publication of the MTH typology, two subsequent studies by Hanzlick and Kaponen (1994) and Felthous and Hempel (1995) made additions to the typology to include more demographic variables, manner of death, precipitating factors, and psychological variables. Using the full MTH typology, with or without the contributions of later researchers, results in a near-comprehensive taxonomy with hundreds of possible combinations. Adding more variables may allow for the exact classification of more and more individual murder-suicide incidents. 
However, the result is that "parsimony gives way somewhat to comprehensiveness" (Joiner, 2014, p. 123). Trying to explain every relationship, demographic, situational, and psychological variable is exhausting. The ultimate goal of such a typology — to reduce a varied phenomenon to a meaningful and applicable number of subgroups - is lost. Classic cognitive psychology research has supported that the average human can remember and meaningfully use a finite number of things — words, categories, or chunks of information — at one time (Miller, 1956). Usability is likely the reason that researchers who cite the MTH typology (and the original researchers themselves) have limited their discussions to the five most common motives and motive and relationship combinations of murder-suicide described in this manuscript (Liem, 2010; Yip et al., 2011).

Joiner's perversion of virtue (POV) typology. Effective categorization is succinct, yet informative. A new taxonomy of murder-suicides, developed by Joiner (2014) as part of a larger theory of murder-suicide, attempts to provide usefulness paired with brevity. This yet unapplied taxonomy groups murder-suicides by motive only. The motives are described as being "perversions" of the following virtues: mercy, justice, duty, and glory (Joiner, 2014). Murdersuicides driven by mercy are those in which the perpetrators kill loved ones in order to prevent any suffering or harm the perpetrator believes loved ones will undergo upon the perpetrator's death by suicide. This motive may encompass such incidents as spousal declining-health murdersuicides or familicide-suicides following a job loss. Justice-motivated murder-suicides are those in which a perpetrator feels slighted in some way and seeks to correct a perceived injustice prior to his or her death by suicide. Examples of this type include those perpetrators who kill either a former employer after being fired or a former romantic partner who has since terminated a relationship. Murder-suicides that are motivated by duty involve the killing of dependents - those 
that are the responsibility of the perpetrator-so that others will not be burdened with the perpetrator's former obligations. Duty-motivated scenarios include the killing of a child, ill spouse, or disabled relative prior to suicide such that the caretaking responsibilities are not passed on to others upon the perpetrator's suicide. Finally, murder-suicides motivated by glory are those in which perpetrators kill for post-mortem notoriety. The most frequently sensationalized types of murder-suicides - those involving suicide bombings or mass shootings - fit the glory motive. Potential applications of the POV typology will be discussed later in the manuscript in the context of Joiner's murder-suicide theory (2014).

The perverted virtues typology is a promising theory that has yet to be empirically or independently applied. That it is based solely on the motive for the murder-suicide makes it an efficient way to classify these types of incidents. One potential obstacle to the practical implementation of such a classification system is that motive is not always readily apparent in brief police, medical, or newspaper reports of murder-suicide. The sex of the perpetrator, the weapon type, the manner of death, and victim-perpetrator relationship are all highly likely to be identified post-mortem. But, even when a psychological autopsy is conducted, motive may not be clear to those closest to the murder-suicide perpetrator. Furthermore, those closest to the perpetrator are the most likely to be victims in murder-suicide incidents. If motive is to be the primary source of classification in this typology, strong operational definitions must be developed that allow researchers to reliably surmise motives even when presented with limited information. This can be accomplished by carefully identifying common features of murdersuicide incidents that provide enough evidence to allow a researcher to reasonably infer one motive over another. For instance, given the vague narrative of a woman who kills her exhusband within one year of their divorce by poisoning him, one may reasonably conclude that 
the motive was likely justice for perceived wrong. The development of a reliable and valid set of operational definitions for coding derived perverted virtue motives is a substantial contribution of the present manuscript. Dr. Joiner reviewed and provided feedback on the operational definitions we developed for the perversion of virtue theory motives (personal communication, January 5, 2015).

\section{How is Murder-Suicide Studied?}

Murder-suicide incidents pose some distinctive challenges that make study of this phenomenon difficult. First, the actors in such events do not live to provide interviews or other pertinent information that may assist researchers in understanding murder-suicide. Researchers use whatever information the perpetrator leaves behind as well as information aggregated from additional sources such as family members, law enforcement, medical responders, and journalists who chronicle these events. Further complicating the study of murder-suicide is the fact that those individuals closest to the perpetrators are often victims. Another major challenge is that murder-suicides are relatively rare events. To achieve large enough samples to employ statistical tests, individuals who study murder-suicides combine cases from a wide geographic range and/or wait several years for incidents to accumulate. Researchers have developed some inventive workarounds for these limitations. Historically, examining police, psychiatric, or medical examiner records have been among the primary methods for acquiring data on murder-suicide incidents (Hanzlick \& Koponen, 1994; Stack, 1997). This methodology can provide detailed data that may be "used to reconstruct the chain of events that led to the [murder]-suicide" (Stack, 1997, p. 438). One drawback is that such studies "often involve intense investigations of a small number of cases" typically performed "at the local level” (Stack, 1997, p. 438). 
Striving for a more geographically representative sample, Malphurs and Cohen (2002) chose newspaper surveillance via LexisNexis and the Newspaper Association of America as their method for finding cases of murder-suicide incidents in the United States. While this method yielded 673 incidents over a three-year period, the amount of detail provided about incidents varied widely. The number of murder-suicides observed via this method over three years is less than the expected annual number of national murder-suicides. The authors indicate that the sample is not likely to be representative due to editorial discretion in publishing stories of murder-suicides and overrepresentation of newspapers from less populous regions (Malphurs \& Cohen, 2002). News surveillance has been used in other studies (Salari \& Sillito, 2016), most notably in the Violence Policy Center's (2012) “American Roulette” series of studies on murdersuicide in the United States.

Within the past three decades, databases tracking violent deaths at state and national levels have emerged allowing for the tracking of murder-suicides (Flynn et al., 2009; Liem \& Nieuwbeerta, 2010; Paulozzi, Mercy, Frazier, \& Annest, 2004). Both the Netherlands and Switzerland have national monitoring systems that record homicides (Liem et al., 2011). In the United States, the National Violent Death Reporting System (NVDRS) is the preeminent dataset for the study of violent deaths, including murder-suicides. It has grown out of local and state surveillance systems to include data from up to 32 states (CDC, 2015; Paulozzi et al., 2004). Though the current absence of data from all states renders the "national" part of the NVDRS a misnomer, the NVDRS is among the richest surveillance systems for violent deaths in existence and is "uniquely equipped to study homicide/suicide" (Bossarte et al., 2006, p. ii33). 


\section{Emerging Topics in the Study of Murder-Suicide}

Female-Perpetrated Murder-Suicide. As continued reviews of the murder-suicide literature have been published, little new information has been gleaned regarding the major facets of murder-suicide. In Eliason (2009), Liem (2010), and Panczak et al. (2013) — as in Marzuk et al. (1992) before them—-males are found to be the overwhelming perpetrators of murder-suicide incidents in the United States. Female romantic partners are still the most likely victims, and firearms remain the most likely lethal instrument in U.S. murder-suicides. As previously stated, the vast majority of information known about murder-suicide is derived from heavily male samples and thus reflects characteristics of male-perpetrated murder-suicide. Few studies have examined sex differences in murder-suicide or female murder-suicides alone. And, because female-perpetrated murder-suicide incidents are atypical within an already rare phenomenon, those studies that do include female perpetrators are often small in sample size ${ }^{1}$. The following studies have examined female-perpetrated murder-suicide and/or have obtained relatively substantial sample sizes of female murder-suicide perpetrators.

Fishbain, Rao, and Aldrich (1985) compared 10 female murder-suicide perpetrators to samples of 50 female murder-suicide victims and 50 female suicide decedents on variables associated with residence, violent death, and history of depression. The murder-suicide perpetrators $(40 \%)$ were found to be less likely than suicide decedents $(92 \%)$ to have a recent history of depression. Four of the 10 female murder-suicide perpetrators left suicide notes, and seven of the 10 incidents occurred on weekends. Current or former romantic partners were killed in six of the 10 female-perpetrated murder-suicides.

\footnotetext{
${ }^{1}$ Malphurs and Cohen (2002) identified 59 female murder-suicide perpetrators among their sample of 674 murdersuicide perpetrators in a newspaper surveillance study. However, no sex specific incident factors are reported nor are comparisons made by sex of perpetrator.
} 
Logan et al. (2008) identified 35 females in a sample of 408 murder-suicide perpetrators obtained via the U.S. National Violent Death Reporting System (NVDRS) database from the years 2003-2005. With regard to murder-suicide relationship type, 17 (48.6\%) females killed children, while $11(31.4 \%)$ murdered intimate partners, three (8.6\%) killed intimate partners and an additional person, and two each killed other related family members (5.7\%) and individuals outside of the family $(5.7 \%)$. Females were the minority perpetrator sex in all murder-suicide victim-perpetrator relationship types, except filicides in which the 17 female perpetrators $(51.5 \%)$ were slightly more prevalent than the 16 male perpetrators. Most $(60 \%)$ of the female perpetrators were aged 20-49 years, and were of White (82.9\%) and non-Hispanic (91.4\%) race and ethnicity. Those were also the predominant age, race, and ethnic categories among female suicide decedents, male suicide decedents, and male murder-suicide perpetrators in the study.

In a 2009 study classifying murder-suicides by victim relationship and motive in HongKong via cluster analysis, Yip and colleagues identified 31 female perpetrators of murder-suicide (though two were eliminated from analyses for a lack of information). Six types of murdersuicide were derived from the cluster analysis. Half of the perpetrators $(n=5)$ in one clusterconflicts with children-were females, while 10 (76.9\%) of the 13 perpetrators in the mentally ill cluster were females. Females made up the minority in the dispute with family members $(\mathrm{n}=1$; $10 \%)$, dispute with a person outside of the family $(\mathrm{n}=1 ; 5.5 \%)$, altruistic $(\mathrm{n}=5 ; 33.3 \%)$, and conflict in a spousal relationship $(n=7 ; 30.4 \%)$ clusters. Data in the clusters were not presented by sex. Of the predominantly female clusters, jumping $(84.6 \%)$ was the primary suicidal method used among the mentally ill cluster of perpetrators, and charcoal burning leading to asphyxiation (50\%) was most often used among the conflicts with children cluster. It is important to note the 
cultural impact of the leading suicide methods in this study, as firearm availability is greatly reduced and thus not a common method of suicide or murder-suicide in Hong Kong.

Historically, female-perpetrators of murder-suicide are best represented in the filicidesuicide type of murder-suicide incidents (Marzuk et al., 1992). Logan, Walsh, Patel, and Hall (2013) used the NVDRS database to examine 129 filicide-suicide and familicide-suicide incidents in the United States, 31 (24\%) of which were female-perpetrated. Females perpetrated three (10\%) of the 30 familicide-suicide incidents and $26(39.4 \%)$ of the filicide-suicide incidents. A greater percentage of female perpetrators had evidence of current or historical mental health problems or treatment than did male perpetrators. The authors also indicate that over $48 \%$ of the female perpetrators were divorced, widowed, or separated.

Characteristics of female murder-suicide. Several studies have indicated that the most likely victims of female-perpetrated murder-suicides are children (Adinkrah, 2003; Chan et al., 2003; Felthous \& Hempel, 1995; Marzuk et al., 1992; Roberts, Wassenaar, Canetto, \& Pillay, 2010). Female perpetrators are more likely than males to use strangulation, poisoning, and suffocation in lieu of firearms (Marzuk et al., 1992). Female perpetrators tend to be aged 20-49 years, the typical range to have young children in the home (Logan et al., 2008). Female murdersuicide perpetrators are often found to have more current and historical psychiatric diagnoses (particularly depression), suicidality, and treatment than male murder-suicide perpetrators (Fishbain et al., 1985; Logan et al., 2008). Despite a relatively high rate of mental health provider contact, female murder-suicide perpetrators are an understudied and clinically-relevant subgroup. Less is known regarding motive, but female perpetrators are most often thought to act for reasons of altruism — similar to Joiner's (2014) mercy and duty motives — or as a by-product of mental illness (Marzuk et al., 1992; Yip et al., 2011). Further research, with larger sample 
sizes, is needed to more thoroughly examine the sex-specific characteristics of female murdersuicide - particularly as they relate to motive, mental illness, substance use, domestic violence, and other potentially actionable variables. In the present study we compare demographic, incident, and psychological variables among female and male murder-suicide perpetrators as well as male and female suicide decedents. Doing so helps to identify whether female perpetrated murder-suicide is distinct from murder-suicide perpetrated by males and should be examined separately.

Joiner's Perversion of Virtue (POV) Theory. Thomas Joiner is among the leading contemporary researchers and theorists in the study of suicidal behavior. His 2005 book, Why People Die by Suicide, introduced his interpersonal-psychological theory of suicide (IPTS). The IPTS posits that individuals die by suicide when three factors converge: the individual has acquired the capability to enact self-harm via previous exposure to painful and provocative events, the individual perceives that he or she is a burden on others, and the individual subjectively experiences a failure to meaningfully connect (or belong) with others (Joiner, 2005). The IPTS has become an influential theory that has spawned research interest as evidenced by over 1000 estimated citations of the book and over 500 estimated citations of the seminal article on the theory (Google Scholar, 2015; Joiner, 2005; Van Orden et al., 2010).

Joiner's (2014) Perversion of Virtue: Understanding Murder-Suicide outlines a novel theory of murder-suicide that diverges from the majority of the extant literature on the topic in several meaningful ways. First and foremost, Joiner's classification of murder-suicide by motive alone is a deviation from the complex array of victim-suspect relationship and motive combinations that comprise other classification systems (Marzuk et al., 1992; Hanzlick \& Koponen, 1994). Joiner (2014) asserts that in his theory "all murder-suicides fit within four 
categories" (p.123). Achieving comprehensive murder-suicide classification with so few categories, defined by motive alone, would be more efficient than current taxonomic strategies and novel if the categories prove to meaningfully differentiate classes of murder-suicide incidents. To date, the Perversion of Virtue taxonomy has not been tested to see whether it divides murder-suicides in a meaningful way or classifies murder-suicides comprehensively.

At the core of the Perversion of Virtue theory of murder-suicide is Joiner's take on the debate about whether murder-suicide is a type of murder or suicide or its own entity. Joiner (2014) makes the definitive statement that "genuine murder-suicides...start with the decision to die by suicide" (p. 12). Joiner's argument is originally theoretical—-that all murder-suicide is "derivative of a decision to die by suicide" (p. 39) - but is supplemented by supporting evidence from empirical literature. Joiner (2014) asserts that studies by Eliason (2009) and Malphurs and Cohen (2002) indicate that the rate of substance use by murder-suicide perpetrators more closely resembles that of suicide perpetrators than homicide perpetrators. Another observed commonality often shared by murder-suicide and suicide, but seldom by homicide, is the presence of mood disorders among perpetrators (Liem \& Roberts, 2009). Furthermore, Joiner (2014) acknowledges the finding that murder-suicide rates more closely resemble homicide rates than suicide rates (Large et al., 2009), but also describes another epidemiological study, Milroy (1995), that has found suicide and murder-suicide rates remain relatively stable, while murder rates have decreased. Joiner (2014) has offered the most definitive conclusion among recent researchers, though his assertion that murder-suicide is a subtype of suicide is strongly driven by theory. Some of that theory comes from his interpersonal-psychological theory of suicide (IPTS), specifically the interpersonal nature of both acts. While in the IPTS perceived burdensomeness and a failure to meaningfully belong with others are two of the three preconditions for suicide, 
the perversion of virtue (POV) theory states that the decision to die by suicide is primary and decisions to then kill others are driven by perversions of interpersonal virtues (Joiner, 2005; Joiner 2014).

\section{Research Aims and Hypotheses}

The first aim of the current research was to examine potential differences in male and female-perpetrated murder-suicide. Given the relatively infrequent occurrence of femaleperpetrated murder-suicide, it is often grouped together with male-perpetrated murder-suicide in statistical analyses effectively overshadowing any potentially distinctive aspects of femaleperpetrated murder-suicide. The present study, with the largest known sample of female murdersuicide perpetrators, is uniquely suited to study sex differences in murder-suicide perpetrators. Sex differences among murder-suicide perpetrators with regard to demographic, mental health, and incident characteristics were examined. Female perpetrators of murder-suicide were expected to experience more historical mental health diagnoses and treatments, display more suicidal intent, attempt suicide more, and experience more interpersonal violence victimization than male perpetrators. Female murder-suicide perpetrators were expected to be less likely than males to use firearms, less likely to abuse drugs and alcohol, less likely to perpetrate interpersonal violence and more likely to have child victims. No difference in age, race, ethnicity, or marital status was expected.

A second aim of the current study was to evaluate Joiner's (2014) perversion of virtue theory of murder-suicide beginning with the murder-suicide motives. Operational definitions of the four motives - mercy, justice, duty, and glory — were developed and used to code murdersuicide narratives (see Appendix A for examples of narratives). The interrater reliability of results using the POV codes were compared to interrater reliability of the same narratives coded 
using operational definitions of the Marzuk, Tardiff, and Hirsch (1992) motive types. The narrative incidents coded via the POV motive types were cross-tabulated with the incidents coded by the MTH motive types to see whether the POV motives can be used to group murdersuicide cases in a novel way. There was some expected overlap among the typologies; the amorous jealousy and retaliation MTH motive types were expected to overlap heavily with the justice motive type from the POV theory. The POV mercy motive was expected to overlap predominantly with the declining health/mercy motive in the MTH typology.

Additionally, the percentage of incidents coded as one of the four motives of the POV typology can be used to examine the hypothesis that this theory is universal; if the POV theory is universal, one would expect nearly all murder-suicide incidents would fit one of the four motive types and not in the undifferentiated or unknown categories. Differences in demographic characteristics, mental health variables, and incident characteristics were expected if the POV motives meaningfully classify distinct murder-suicide types. For instance, mercy and duty perpetrators were expected to be older than justice and glory perpetrators. Justice-motivated perpetrators would be expected to kill more intimate partners for relationship dissolution reasons, while mercy-motivated perpetrators were expected to kill intimate partners or children in poor physical health. Furthermore, an ancillary analysis tested the assumption that murder-suicide is a type of suicide using logistic regression comparisons of demographic and psychological variables between the two incident types. The present research-by testing assumptions of the POV theory - is among the first applications of the theory to real world data.

Beyond increasing our understanding of an understudied sub-population and testing a novel theory of murder-suicide, the present study sought to generate relative findings that can be translated to mental health practice. A number of potentially actionable variables were studied in 
the present investigation in order to inform clinician awareness, assessment, and intervention as it relates to potential perpetrators of murder-suicide. To be considered a potentially actionable variable, there must be a reasonable chance for detection and preventative intervention prior to murder-suicide. Mental health diagnoses, substance dependence, and domestic violence remain meaningful and potentially actionable variables of study in murder-suicide incidents.

Comparisons between murder-suicide and suicide incidents on potentially actionable variables have direct implications for clinical practice. For example, if murder-suicide were found to mirror suicide on the previously-listed variables, then perhaps "suicide prevention is also murder-suicide prevention" (Joiner, 2014). However, if murder-suicide perpetrators-or specific subsets of murder-suicide perpetrators (e.g., by sex, motive)—differ substantially on these types of variables, then that information could meaningfully inform different approaches to clinical practice.

\section{Method}

\section{Data Source}

All cases were obtained through the Centers for Disease Control and Prevention's (CDC) National Violent Death Reporting System (NVDRS) Restricted Access Database (RAD). The database consists of various characteristics of violent deaths - homicide, suicide, murder-suicide, accidental firearm deaths, legal intervention, and deaths of undetermined intent — from eighteen states (at the time of data acquisition) ${ }^{2}$. The database is organized to link the individual's murder

\footnotetext{
${ }^{2}$ At the time the dataset was acquired data was available from these 18 states: Alaska, Colorado, Georgia, Kentucky, Maryland, Massachusetts, Michigan, New Jersey, New Mexico, North Carolina, Ohio, Oklahoma, Oregon, Rhode Island, South Carolina, Utah, Virginia, and Wisconsin. In 2014, an additional 14 states were added to the NVDRS. Data from these states is not included in the current studies: Arizona, Connecticut, Hawaii, Illinois, Indiana, lowa, Kansas, Maine, Minnesota, New Hampshire, New York, Pennsylvania, Vermont, and Washington.
} 
with the perpetrator's completed suicide, if it is within 24 hours/one calendar day of the homicide. Trained data abstractors code data from primary sources like death certificates, coroner/medical examiner reports, law enforcement reports, and crime lab data, and secondary sources like supplementary homicide reports and hospital or emergency room data, among others (Steenkamp et al., 2006). Demographic, situational, weapon, toxicology, and mental health variables were among those collected. While the majority of such data is binary or categorical, narrative accounts derived from police and coroner/medical examiner reports were provided when available. Appendix A contains examples of medical and law enforcement narrative accounts of murder-suicide incidents.

\section{Data Access, Case Finding, and Estimated Sample Size}

A formal application was submitted to the CDC for approval prior to receiving access to the data. At the time of receipt, the dataset contained 107,707 violent death incidents from 2003 through the end of 2010. Violent deaths were designated with a "person type" variable that indicated whether the subject in each incident was a victim, a suspect, or both a victim and a suspect. Dual victim-suspects made up 1519 cases of the original 107,707 violent death incidents. The majority of victim-suspects were cases of murder-suicide but other incidentssuch as dual murders, homicide or suicide preceded or followed by undetermined or accidental deaths - may be classified as incidents in which the subject is both a victim and a suspect in the incident. It is necessary to carefully scour the data for cases of genuine murder-suicide. The present study used criteria established by McNally, Patton, and Fremouw (2016) to eliminate the following victim-suspect incidents that were not murder-suicides: incidents in which murder and suicide were separated by more than one calendar day, dual homicide incidents, legal intervention deaths, attempted murder-suicides, accidental deaths, deaths of undetermined intent, 
and cases where narrative data were absent. As previously discussed, Joiner (2014) has advocated for the retaining of murder-suicide cases with more than one calendar day between violent events if there is evidence of continuity of process between murder and suicide. Given that NVDRS abstractors are trained to link cases in which an individual is a suspect and victim in incidents that occur within 24 hours or one calendar day of one another, few cases in the dataset were expected to have a murder and suicide separated by more than one calendar day. Incidents in which murder and suicide are separated by more than one day were eliminated to maintain consistency of the NVDRS one calendar day coding rule across incidents.

Using the same initial NVDRS sample as the present study, McNally and colleagues (2016) determined just over $12 \%(\mathrm{n}=189)$ of 1519 incidents with victim-suspect person type were not able to be confirmed as murder-suicides. Of the 189 removed cases, 80 were dual homicides, 75 were legal intervention deaths (i.e., incidents in which a homicide perpetrator was killed by law enforcement), 16 provided no narrative data, 11 were cases of unrelated murder and suicide or cases in which the murder and suicide were separated by more than one calendar day, five were cases of suicide following accidental/undetermined deaths, and two were homicide incidents prior to undetermined or accidental deaths. The remaining sample of 1330 incidents included 90 cases of female-perpetrated murder-suicide. The same number of female murder-suicide perpetrators will be used in the present study, and such a sample will be more than double the population of female murder-suicide perpetrators obtained in the largest retrievable studies.

\section{Sample Selection}

All 90 observed cases of female murder-suicide in the sample were determined to be true murder-suicides via the previously-described criteria and were included in the analyses. Cole 
(1980) recommended when "only a small number of cases is available for study...the selection ratio should be increased to two, three, or even four controls per case" (p. 27). In accordance with this recommendation, samples of male murder-suicide perpetrators, female suicide decedents, and male suicide decedents $(\mathrm{n}=180)$ equaling twice the number of female murdersuicide perpetrators $(n=90)$ were sampled from those respective populations in the NVDRS dataset. Doubling the sample size allowed for increased power in statistical analyses (e.g., more variables were able to be tested in logistic regression; Peduzzi, Concato, Kemper, Holford, \& Feinstein, 1996). Samples of male murder-suicide perpetrators as well as male and female suicide decedents were matched to the female murder-suicide sample based on the year and state in which the respective incident occurred. In this matching procedure, two matches were randomly selected for each female murder-suicide from a pool of all eligible state and year matches. In three cases, only one male murder-suicide year and state match was found for a given female murder-suicide case. To find the additional match for these three cases, an additional male murder-suicide case was randomly selected from all male murder-suicide cases occurring that year. Thus, three male murder-suicide cases are matched to female murder-suicide cases by year of incident alone because no eligible year and state of incident matches were present in the dataset. All male and female suicide decedent matches are matched to female murder-suicide cases by year and state.

While it would have been advantageous to select and compare homicide-only perpetrators as well, the NVDRS is limited in that it provides data on individuals who are deceased. Narrative data on suspected homicide perpetrators is infrequently recorded in the current dataset. Logan and colleagues (2008) compared demographic data from homicide suspects to murder-suicide perpetrators and noted the following limitation: "Because the 
NVDRS is a violent death surveillance system, less information is available with respect to the characteristics of suspected perpetrators who are still living. Therefore, we were unable to compare homicide-suicide perpetrators with homicide only suspects..." (p. 1058). The same limitation holds true for the current version of the NVDRS, and so "homicide only" suspects were not compared in this study.

\section{Data Coding Procedures for Murder-Suicide Motives}

Operational definitions and coding rules were developed for each of Joiner's (2014) perversion of virtue motives for murder-suicide (Appendix B) and each of Marzuk, Tardiff, and Hirsch's (1992) murder-suicide motives (Appendix C). Because of the novelty of the POV motive types, Joiner was consulted and provided feedback to support the content validity of the operational definitions (personal communication, January 5, 2015). Each narrative case (consisting of medical and/or police reports on one murder-suicide incident; Appendix A) was coded for murder-suicide motive by three trained undergraduate raters. Raters provided two types of codes. First, a rater was asked to identify whether each motive was present or absent for each case. Second, the rater was asked to assign a primary code-the most likely reason the perpetrator committed the offense based on the narrative data- to the case. Two sets of three raters coded one half of the data using the MTH typology and the other half of the data using the POV typology. Raters coded a given case using only one typology. A total of three independent rater codes were provided for each case. Three raters coded half of the data using the MTH codes first, and three raters coded half of the cases using the POV codes first. The sets of raters then coded the other half of the data using the opposing coding scheme-either MTH or POV typology. 
Rater Training. Prior to rating the motives found in narrative incidents from a given typology, each of the six raters completed a formal training process. First the coding manuals (Appendices A and B) were carefully reviewed with the rater. Next, the rater and principal investigator read sample narratives (narratives of male murder-suicide incidents form the NVDRS not sampled in the present study) and engaged in dual coding of motives from the sample scheme. When the rater expressed understanding of the rating system and had no further questions, both the rater and the principal investigator independently rated between 50 and 100 sample cases. Successful completion of training was measured by reaching an $80 \%$ agreement criterion with the principal investigator on independent ratings of the primary motive on at least 50 cases. Following the first 50 independent ratings, completion criterion was calculated, any disagreements in coding were discussed, and clarifying feedback was provided while re-coding the disagreed upon cases together. If the rater did not meet criterion after 50 cases and/or 75 cases, an additional 25 cases were independently coded and the criterion measurement and corrective feedback procedures were repeated. Each rater completed this training regimen on two independent occasions - once for the MTH coding system and once for the POV coding system. All raters achieved the $80 \%$ coding agreement criterion for each motive type after rating 50 to 100 practice narratives.

Rater Coding and Procedures for Combining Raters' Codes. A total of 270 murdersuicide incidents were coded for motive by each of six independent, trained raters using the aforementioned coding techniques. Each incident was coded by three of the six independent raters using the POV codes and was coded again by the other three raters using the MTH codes. Interrater reliability of the presence/absence ratings and primary motive ratings for each incident were calculated with regard to the POV and MTH motive code types (Table 1). Krippendorff's 
alpha was used as it is a robust measure of interrater agreement calculations among more than two raters and is also appropriate to use with missing data and with a range of levels of data measurement (i.e., dichotomous, nominal, interval, etc.; Krippendorff, 2008). In order to facilitate data analyses, the three coders' motive ratings for each incident were merged into a single code for the given typology. Generally, codes identified by a majority (at least two of three) of the raters were used as the merged code. When raters disagreed or no majority was present, the coding rules in Appendix D were used to merge the three raters' codes.

\section{Variables}

The first type of variables examined in analyses were grouping variables such as the sex of the perpetrator, the person type (murder-suicide perpetrator or suicide decedent), and the ratercoded POV and MTH motives if applicable. Age, race (white, black, American Indian, Asian/Pacific Islander), ethnicity (Hispanic/Latino/Spanish origin, non-Hispanic/Latino/Spanish origin), and marital status (ever married, never married/unknown) were also examined. For logistic regression analyses, race, ethnicity, and marital status were transformed into categorical variables in which each perpetrator was rated as either the majority category (White, nonHispanic, and previously married) or not. Because groups were matched by year and state of incident, neither variable was appropriate to include in analyses.

The next set of variables examined were those potentially actionable mental health variables relating to mental health, substance abuse, interpersonal violence, and weapon use. Any history of drug and alcohol abuse was coded dichotomously (present, absent/unknown) as was any current or prior mental health problem. Whether the perpetrator or decedent reported any suicidal intent (that was before the respective fatal act and intervenable, not merely during the act), left a suicide note, had a history of suicide attempt(s), was the perpetrator of interpersonal 
violence in the past month (not including the murder-suicide incident), was the victim of interpersonal violence in the past month, or used a firearm as the primary weapon in the incident were all coded dichotomously (present or absent/unknown). Additional variables of interest were examined, such as whether a murder-suicide perpetrator had a current or former romantic partner as a victim, a child (includes biological, adoptive, stepchild, or grandchild) as a victim, the mean age of victims (if known), and the number of victims.

\section{Analyses and Research Aims}

Descriptive statistics on the major variables of study are reported on major groups and subgroups (e.g., male and female murder-suicide perpetrators; suicide decedents and murdersuicide perpetrators). Variables that are exclusive to murder-suicide incidents (e.g., victim and motive characteristics) are reported for murder-suicide subgroupings only.

First, binomial logistic regression was used to test whether demographic, psychological, and incident variables were differentially associated with male versus female murder-suicide perpetration. Next, we initially planned to use multinomial logistic regression to assess whether the four POV primary motive codes divided murder-suicide incidents into groups that were differentially predicted by mental health, demographic, and incident characteristics; however, only two of the four primary POV motive codes were endorsed by raters frequently enough to be included in analyses. As such, a binomial logistic regression was used to assess whether the two regularly-endorsed primary POV motive codes divided murder-suicide perpetrators into groups that were differentially predicted by mental health, demographic, victim, and incident characteristics.

Then. two multinomial logistic regression analyses were used to assess whether the five MTH primary motive codes divided murder-suicide incidents into groups that were differentially 
predicted by mental health, demographic, and incident characteristics. While two multinomial logistic regressions did not permit all possible comparisons among five MTH motive groups, completing five multinomial logistic regressions would have unnecessarily increased the risk of obtaining spurious group differences simply due to the number of tests conducted. We wanted to strategically select reference groups that had moderate (relatively average) demographic characteristics and variable frequencies so that observing group differences would allow for conclusions regarding whether the MTH motive typology was separating murder-suicide incidents into meaningfully different groups. Some groups were determined not to be good reference groups because of notable differences apparent when examining demographic characteristics and variable frequencies (Table 6). For instance, the declining health-motivated perpetrators had a substantially higher mean age than other groupings. Amorous jealousymotivated perpetrators were represented by the highest rates of males, interpersonal violence perpetration, and firearm use. Using this rationale, the altruistic/extended suicide and retaliation motive groups were determined to be relatively moderate with regard to frequency and percentage data. These groups were selected as reference groups in order to ensure statistical comparisons with groups that appeared similar in Table 6.

Crosstabulations were used to examine how murder-suicide cases were coded on one motive classification (MTH or POV) with respect to the other classification type, and Krippendorff's alpha was calculated to measure and compare the interrater reliability of motive coding for both MTH and POV typologies. Finally, an additional facet of Joiner's Perversion of Virtue Theory, that murder-suicide perpetrators are a subset of suicide, was tested. A binomial logistic regression model including demographic, mental health, and incident characteristics was used to predict incident type (murder-suicide or suicide) in order to test the POV theory 
assumption that murder-suicide perpetrators are a subset of suicide perpetrators and therefore were not differentially predicted by the variables in this model. Statistical analyses were conducted using IBM SPSS statistics version 23.0.

\section{Results}

\section{Comparing Sex of Murder-Suicide Perpetrators}

Descriptive statistics regarding male and female murder-suicide perpetrators are reported in Table 2. Perpetrator sex was predicted by a logistic regression model of demographic (i.e., age, marital status), psychological (i.e., history of mental health diagnosis/treatment, history of substance abuse diagnosis/treatment, history of suicide attempts, disclosed intent to die by suicide, or interpersonal violence perpetration in the past month), victim (i.e., number of victims, at least one victim was a romantic partner of the perpetrator, at least one victim was a child of the perpetrator) and incident (i.e., used a firearm, left a suicide note) characteristics (Table 3). A test of the overall model against a constant was significant, indicating that the set of predictors reliably distinguished between male and female murder-suicide perpetrators, $\chi^{2}(12)=86.51, p<$ $.001, R^{2}=.27$ (Cox \& Snell) and .38 (Nagelkerke). The model correctly predicted perpetrator sex in $78.1 \%$ of cases.

The following variables did not differentially predict male versus female murder-suicide perpetration in the logistic regression: perpetrator age, ever having been married, any history of substance abuse, historical suicide attempts, disclosing suicidal intent, leaving a suicide note, using a firearm during the murder-suicide, enacting interpersonal violence in the month prior to the murder-suicide, victim age, and having a current or former romantic partner as a victim. Female perpetrators of murder-suicide were significantly more likely to have a current or historical mental health diagnosis or to kill a child (biological, adoptive, step, or grand). A one- 
unit increase in number of victims was associated with increased odds ${ }^{3}$ of female murder-suicide perpetration (Table 3).

\section{Comparing Murder-Suicide Motive Typologies}

Perversion of Virtue (POV). Demographic and frequency data for perversion of virtue motive categories can be seen in Table 4. Only mercy and justice primary codes were recorded with sufficient frequency to be analyzed separately; one incident received a primary code of duty and zero incidents were primarily coded as glory. A logistic regression model of demographic, psychological, relationship, and incident variables was found to significantly predict whether murder-suicide incidents were coded as the perversion of virtue motives mercy or justice, $\chi^{2}$ (13) $=93.37, p<.001, \mathrm{R}^{2}=.37$ (Cox \& Snell) and .53 (Nagelkerke; Table 5). This model correctly categorized $82.8 \%$ of cases as either justice or mercy-motivated murder-suicides. Justicemotivated murder-suicides were associated with younger perpetrator age and male sex when compared to mercy-motivated murder-suicides. Mercy-motivated murder-suicide perpetrators were more likely to leave a suicide note or to have a child victim than justice-motivated murdersuicide perpetrators.

Multiple POV motives endorsed. When examining purely the presence or absence of motives, as opposed to the primary motive codes used in logistic regression, six cases were found to have more than one POV motive code. Of these, five cases were dual coded as mercy

\footnotetext{
${ }^{3}$ Logistic regression analyses produce odds ratios, which form the basis for group comparisons in the present study. Odds ratios are calculated as: (the number of cases from group A that experience a given variable/ the number of cases from group $A$ that do not) divided by (the number of cases from group $B$ that experience a given variable/ the number of cases from group $B$ that do not). Odds ratios are not relative risk calculations. It is inappropriate to use the odds ratio as relative risk to say that one group was $\mathrm{X}$ times more likely than another to experience for a given variable, and such language is not used in the current manuscript. Odds ratios over 1.0 overestimate relative risk, while odds ratios under 1.0 underestimate relative risk (Davies, Crombie, \& Tavakoli, 1998).
} 
and duty motivated incidents with a primary code of mercy. One was coded as a dual duty and glory motive and given a primary motive of duty.

Marzuk, Tardiff, and Hirsch (MTH). Demographic and frequency data for MTH motive categories can be seen in Table 6 . All five primary motive codes were endorsed for at least 16 cases. Two multinomial logistic regression analyses were conducted with MTH motive type as the dependent variable. Retaliation and altruistic/extended suicide were selected as the reference groups for the two multinomial logistic regressions based on their similarity to other groups on demographic, psychological, and incident variables in Table 6.

Retaliation as the reference category. A logistic regression model of demographic, psychological, relationship, and incident variables was found to significantly predict whether murder-suicide incidents were coded as different MTH motive categories with retaliation serving as the reference category, $\chi^{2}(52)=219.87, p<.001, \mathrm{R}^{2}=.65(\mathrm{Cox} \&$ Snell) and .69 (Nagelkerke; Table 7). Significant main effects of age $\left(\chi^{2}(4)=72.97, p<.001\right)$, sex $\left(\chi^{2}(4)=\right.$ 9.80, $p=.04)$, ever having married $\left(\chi^{2}(4)=13.74, p=.008\right)$, leaving a suicide note $\left(\chi^{2}(4)=\right.$ $16.78, p=.002)$, disclosing intent to complete suicide $\left(\chi^{2}(4)=12.48, p=.014\right)$, perpetrating of interpersonal violence in the month prior to the incident $\left(\chi^{2}(4)=13.66, p=.008\right)$, and having a child victim(s) $\left(\chi^{2}(4)=18.20, p=.001\right)$ were observed.

When retaliation and amorous jealousy-motivated murder-suicide were compared, amorous jealousy-motivated perpetrators were found to have more current or former romantic partner victims and were more likely to have a history of suicide attempts. Retaliation-motivated perpetrators were more likely to have a child victim than amorous jealousy-motivated perpetrators (Table 7). A logistic regression comparing retaliation and declining healthmotivated murder-suicide incidents was conducted. Murder-suicide perpetrators motivated by 
declining health were significantly older than those perpetrators motivated by retaliation.

Declining health-motivated perpetrators were more likely to leave a suicide note and more likely to disclose suicidal intent than retaliation-motivated perpetrators (Table 7).

With regard to retaliation versus altruistic/extended suicide-motivated murder-suicide incidents, altruistic/extended suicide-motivated murder-suicide perpetrators were more likely to be female than retaliation-motivated perpetrators. Altruistic/extended suicide-motivated perpetrators were more likely to leave a suicide note during the fatal incident than retaliationmotivated perpetrators (Table 7). Retaliation-motivated perpetrators were compared to family financial/social stressor-motivated murder-suicide perpetrators. Family financial/social stressormotivated perpetrators were more likely to leave a suicide note, while retaliation-motivated perpetrators were more likely to perpetrate interpersonal violence in the month preceding the murder-suicide (Table 7).

Altruistic/Extended Suicide as the reference category. A logistic regression model of demographic, psychological, relationship, and incident variables was found to significantly predict whether murder-suicide incidents were coded as different MTH motive categories with altruistic/extended suicide serving as the reference category, $\chi 2(52)=219.87, p<.001, \mathrm{R} 2=.65$ (Cox \& Snell) and .69 (Nagelkerke; Table 8). Significant main effects of age $(\chi 2(4)=72.97, p<$ $.001), \operatorname{sex}\left(\chi^{2}(4)=9.80, p=.04\right)$, whether the perpetrator was ever married $(\chi 2(4)=13.74, p=$ $.008)$, leaving a suicide note $\left(\chi^{2}(4)=16.78, \mathrm{p}=.002\right)$, disclosing intent to complete suicide $\left(\chi^{2}\right.$ $(4)=12.48, p=.014)$, perpetration of interpersonal violence in the month prior to the incident $\left(\chi^{2}(4)=13.66, p=.008\right)$, and having child victims $(\chi 2(4)=18.20, p=.001)$ were again observed. 
When comparing altruistic/extended suicide and amorous jealousy-motivated murdersuicide, amorous jealousy-motivated murder-suicide perpetrators were more likely to be male and more likely to have perpetrated interpersonal violence in the month prior to the murdersuicide. Altruistic/extended suicide-motivated perpetrators were more likely to leave a suicide note and were more likely to have a child victim than amorous jealousy-motivated perpetrators (Table 8). When altruistic/extended suicide-motivated murder-suicide incidents were compared to declining health-motivated murder-suicide incidents, declining health-motivated perpetrators were found to be significantly older (Table 8). No significant differences were observed in the predictors between altruistic/extended suicide and family financial/social stressor-motivated murder-suicide incidents (Table 8).

Multiple MTH motives endorsed. When examining purely the presence or absence of coded motives, as opposed to the primary motive codes used in logistic regression, 24 cases were found to have more than one MTH motive code. Of these, nine cases were dual coded as retaliation and family financial/social stressor motives; five were dual coded with declining health and family financial/social stressor motives; three were dual coded with altruistic/extended suicide and family financial/social stressor motives; two were dual coded with amorous jealousy and retaliation motives; and one was dual coded with amorous jealousy and altruistic/extended suicide motives. One case was tri-coded with amorous jealousy, family financial/social stressors, and altruistic/extended suicide motives, while another case was tricoded with altruistic/extended suicide, family financial/social stressors, and retaliation motives. The declining health motive was never dual or tri-coded with either the altruistic/extended suicide or retaliation motives. 
POV and MTH Primary Motive Overlap. A crosstabulation of POV and MTH primary murder-suicide motive codes was conducted (Table 9). Raters using the Perversion of Virtue (POV) coding were able to classify 206 of 270 (76.3\%) murder-suicide cases into one of the four primary motives or a combination (blended) of primary motives. Raters using the Marzuk, Tardiff, and Hirsch (MTH) coding were able to classify 217 (80.4\%) of murder-suicide cases into one of the five primary motives or a combination of primary motives. Forty-seven cases were unable to be coded with a known motive in both the MTH and POV coding schemes. Of the two POV motive codes that were endorsed more than once by raters (Mercy and Justice), cases coded with the POV mercy motive never overlapped with MTH amorous jealousy code, and cases coded with the POV justice code never overlapped with the MTH declining health code. Incidents coded with the POV justice code were most frequently assigned MTH codes of amorous jealousy and retaliation. Incidents coded with the POV mercy code were most frequently assigned the MTH declining health code, while MTH family financial/social stressor and altruistic/extended suicide codes overlapped to a lesser extent with POV mercy codes.

\section{Comparing Suicide Decedents and Murder-Suicide Perpetrators}

Finally, the POV theory assumption that murder-suicide perpetrators are suicide perpetrators led to a binomial logistic regression comparing the two groups by incident type (murder-suicide and suicide). A test of the overall model against a constant was significant, indicating that the set of predictors reliably distinguished between murder-suicide perpetrators and suicide decedents, $\chi 2(12)=435.09, \mathrm{p}<.001, \mathrm{R} 2=.50$ (Cox \& Snell) and .68 (Nagelkerke; Table 10). The model correctly predicted incident type in $84.9 \%$ of cases.

With regard to demographic variables, incident type was not significantly predicted by being White/Caucasian or marital status (having ever been married). Murder-suicide perpetrators 
were more likely to be of Hispanic, Spanish, or Latino origin than suicide decedents. On psychological variables entered into the model, no significant differences in odds of historical drug or alcohol problems, history of suicide attempts, or interpersonal violence victimization within the past month were observed between murder-suicide perpetrators and suicide decedents. Current or historical mental health diagnosis or treatment was significantly more likely for suicide decedents than for murder-suicide perpetrators (Table 10).

Of the known primary mental health diagnoses among suicide decedents, depression was the most common $(126 ; 72.4 \%)$, followed by bipolar disorder $(13 ; 7.5 \%)$, schizophrenia (6; $3.5 \%)$, post-traumatic stress disorder $(3 ; 1.7 \%)$; unspecified anxiety disorder $(2 ; 1.1 \%)$, attention deficit hyperactivity disorder $(2 ; 1.1 \%)$, and unspecified eating disorder $(1,0.5 \%)$. The remaining current or historical primary mental health diagnoses for suicide decedents were unknown. Murder-suicide perpetrators with known mental health diagnoses were also most commonly found to have depression $(26 ; 54.2 \%)$, followed by bipolar disorder $(3 ; 6.3 \%)$, and schizophrenia $(3 ; 6.3 \%)$. The specific diagnoses of other murder-suicide perpetrators with verified histories of mental health diagnosis or treatment were unknown.

Disclosing suicidal intent was more prevalent among suicide decedents than murdersuicide perpetrators. Murder-suicide perpetrators were more likely than suicide decedents to commit interpersonal violence in the month preceding the respective fatal event. For incident variables, both groups were equally likely to leave suicide notes. When compared to suicide decedents, murder-suicide perpetrators were significantly more likely to use a firearm to enact death(s) in their corresponding fatal acts (Table 10). 


\section{Discussion}

\section{Sex of Murder-Suicide Perpetrators}

Male and female perpetrators of murder-suicide had much in common with regard to demographic, psychological, relationship, and incident variables. Unsurprisingly, female perpetrators were more likely to have a history of mental health diagnosis or treatment than males. While females were expected to have higher rates of child victims, it is notable that almost half of female perpetrated murder-suicides involved the killing of a child - a term defined by relationship and not necessarily age. In contrast, children were victims in less than one-tenth of the murder-suicide incidents perpetrated by males. Nearly four fifths of male-perpetrated incidents involved current or former romantic partners as victims, while less than half of femaleperpetrated incidents did. Though this difference was not statistically significant in the presence of covariates in the logistic regression, it further evidence that male and female murder-suicide perpetrators exhibit some distinct group level differences.

The age of victims in female-perpetrated murder-suicides was more variable than the victim age range for males, a finding likely attributable to the differences in victim-perpetrator relationships by sex. Males tended to murder romantic partners and other loosely peer-aged victims (e.g., paramours of their romantic partners, other parties in disputes or fights), while females were almost equally likely to kill romantic partners and children. Females were more likely to perpetrate murder-suicides for reasons of perceived mercy, altruism, or extended suicide (POV mercy type, MTH altruistic/extended suicide motive), motives which are congruent with having child victims (e.g., seen as helpless and/or an extension of the parent and likely to suffer without the parent). 
Firearms were the predominant weapon type for both male and female perpetrators. Both sexes were likely to perpetrate interpersonal violence in the month prior to enacting murder-suicide. It is important to note that though females were found in the logistic regression to be have a significantly greater number of victims per incident than males, the statistically significant difference does not appear to be clinically significant. Both sexes were most likely to have one victim per incident. Females were more likely to have incidents with two victims, while males were more likely to perpetrate incidents with three victims. No female-perpetrated incident had more than three victims, while three male-perpetrated incidents resulted in the deaths of four, six, and seven victims respectively.

Female perpetrators are different in their pattern of mental illness, their victim choice, and their predominant motives for murder-suicide. When murder-suicides are studied in the aggregate, without regard to sex of the perpetrator, these differences are overshadowed by the disproportionate number of male-perpetrated murder-suicide incidents. Even when male perpetrators are represented only twice as frequently as female perpetrators (Table 2), the influence of the unique characteristics of female perpetrators (Table 3) is seemingly erased. This effect is more exaggerated when using unmatched samples where male murder-suicide perpetrators are more than ten times as prevalent as female perpetrators. It is vital to gather more substantial samples of female murder-suicide perpetrators and to report sex-specific data so that preventative efforts can be developed that target this specific subpopulation. Based on this limited amount of data — which happens to be the largest known sample of female murdersuicide perpetrators studied to date - one might reasonably produce some targeted preventative strategies. For example, the current data suggests that female perpetrators are more likely to kill children and are seemingly differentially motivated by perceived altruism, alleviation of 
suffering, and seeing children as extensions of themselves. They are likely to perpetrate interpersonal violence within a month of the incident and approximately one third have had a history of mental health diagnosis or treatment. A professional who encounters a woman who has recently perpetrated interpersonal violence or a clinician treating a mother for a mental health condition may decide to ask some relevant screening questions: Has the individual had thoughts of hurting herself or her children? Does she perceive that her children endure the same emotional pain/suffering or negative experiences that are leading to her own distress? Does she believe that her children would suffer or struggle without her? Increased understanding of female-perpetrated murder-suicide has the potential to lead to more relevant preventative practice, but first we have to take the time to examine female perpetrators and how (if at all) they differ from their male counterparts.

\section{Testing Elements of the Perversion of Virtue Theory (POV) of Murder-Suicide}

Motive Typologies. The Perversion of Virtue (POV) and Marzuk, Tardiff, and Hirsch (MTH) motive typologies were applied to all 270 murder-suicide cases. The motives from the MTH typology appear to be the most frequently used motives in murder-suicide studies and serve as the existing standard. The newly-formulated POV typology aims to be a novel, comprehensive, succinct, and meaningful way to categorize murder-suicide incidents. Identical procedures were used to test the two motive typologies in the following domains: interrater reliability, comprehensiveness, novelty, and meaningful separation of groups.

With regard to interrater reliability, measures from Table 1 indicate that overall MTH and POV motive ratings were approximately equally reliable. It is notable that raters did not assign any ratings of the POV glory motive and only assigned one rating of POV duty out of 270 cases. Each of the five MTH motive types were coded no less than 16 times each. This pattern of rater 
coding may indicate that duty and glory motivated incidents are exceedingly rare events, or perhaps as Joiner (2014, p. 208) noted "an even more parsimonious categorization is workable" such that mercy and duty comprise one motive category, and justice and glory another. While Joiner advocates for the inclusion of all four motives, only two of the motives were readily observed in this sample.

In this specific dataset, motives of duty were difficult to separate from mercy motives. The difference between mercy and duty is much more nuanced than that between mercy and justice. Even with more comprehensive information, we still believe it would prove difficult to infer a duty motive over a mercy motive in the absence of some explicit evidence to the contrary (e.g., recording intent and rationale in some way). In the cases reviewed for this study, sufficient evidence of duty was almost never present. With regard to the absence of glory-motivated incidents there is somewhat more clarity. Killing for the stated reason of post-mortem notoriety has been known to occur, albeit infrequently. The base-rate of glory as a motive within the population of murder-suicides is unknown, but it is likely to be less than one per 270 cases - the current sample size. Inclusion of internet-related (e.g., social media, web pages, video) postings may prove useful in deriving the glory motive after the completion of a murder-suicide, allowing investigators and researchers to become more aware of glory motives than previous generations of investigators.

When comprehensiveness of the coding schemes was assessed, raters using both the MTH and POV coding schemes were unable to classify a notable portion of the cases. In fact, 47 incidents were unable to be assigned a motive in either coding scheme. Raters using the MTH coding scheme were able to assign motives to slightly more cases than those using the POV typology (217 to 206). While the POV typology was not able to comprehensively code the 
murder-suicide incidents, the NVDRS data set included a number of murder-suicide incidents with non-descript police and medical narrative reports similar to the following hypothetical example: 'Male shot and killed another male before turning the gun on himself. Relationship unknown. Circumstances unknown.' In these cases, the inability to derive a motive says more about the quality of the dataset than it does about the coding scheme. Additionally, raters did not report any codes of "other," indicating that all cases not classified as "unknown" were able to be classified as one or a combination of the existing motives.

The next question assessed was the novelty of the POV coding typology. When examining the crosstabulation of cases coded by the MTH and POV classification schemes, it is apparent the POV justice motive type substantially overlaps with the amorous jealousy and retaliation MTH types. The POV mercy typology overlaps with the majority of cases in the MTH declining health, altruistic/extended suicide, and family financial/social stressors motives. The two utilized POV motive types are essentially the result of merging the five MTH motive types into two broad categories of motivation. A higher-order level of classification is a different, but not necessarily novel, way to group murder-suicides.

When examining the logistic regression analyses, it is apparent that the two POV groups are meaningfully different with regard to age, sex, victim selection, and the presence of a suicide note. Examining the logistic regressions of the MTH typologies reveals numerous noted differences between the groups that overlapped with POV mercy (declining health, altruistic/extended suicide, and family financial/social stressors motives) and those groups that overlapped with POV justice (amorous jealousy and retaliation). There are also differences within the MTH types that overlapped with POV justice: amorous jealousy and retaliation. Differences between the MTH types that overlapped with POV mercy-declining health, 
altruistic/extended suicide, and family financial/social stressors motives-were less marked. No significant differences were observed between the altruistic/extended suicide and family financial/social stressors MTH motives. While there is evidence that the two major POV motives are meaningfully different, there is evidence that four of the five MTH motive types appear classify murder-suicide cases into meaningfully different groups. It is likely that the POV typology is assessing a higher-level difference highly related to age, sex, and victim relationship, while the MTH typology classifies murder-suicide into more specific subgroupings that are based on age, sex, and victim relationship, but also on interpersonal violence and suicide-related variables (i.e., historical attempts, intent, and suicide notes).

The binary categorization of motives using the POV typology is certainly parsimonious and it may be clinically useful. Specifically, the mercy-motivated cluster of perpetrators exhibit beliefs - hopelessness, escape from suffering - that overlap with clinical populations presenting for depression. The justice-motivated perpetrators exhibit beliefs - fairness, revenge, aggression - that resemble clinical populations presenting for anger management. While this is an oversimplified analogy, it can help to demonstrate the potential usefulness of identifying two distinct groupings. While this dichotomy is useful, is it specific enough? We can view the two POV motives used by raters in this study as a blunt tool for dividing murder-suicides into two major groups. The MTH typology ratings indicate that more specific groupings based on motive are present. Some of these subgroupings appear to differentiate meaningful sub-groupings. For instance, the individuals who kill for reasons of mercy can be subdivided into an older class that predominantly kills spouses for declining health reasons, and a younger class that kills spouses and children at relatively equal rates for reasons resembling depression and major life stressors (other than declining health). Alternatively, the MTH subtypes of POV justice - retaliation and 
amorous jealousy — appear to be distinguished only by the perpetrator's relationship to the victim and not by some qualitative difference in motive. It appears that there are at least two major motive types, at least one of which (mercy) might be made more useful by more specific subdivision. Other classification systems have increased motive specificity by using other variables and combinations of variables (e.g., age, sex, victim relationship to perpetrator, etc.) to subdivide groups. Subdivision of POV types by other variables would seem to violate some central tenets of the POV theory-parsimony and classification by motive alone. Here is our proposal for a motive-driven solution: use mercy and justice as two main classes of murdersuicide. Within the general justice class, include a glory subtype recognizing that glory may be a special case of justice-motivated murder-suicide in which post-mortem notoriety is seen as the correction of a perceived injustice. The mercy class can be subdivided into cases where perpetrators kill to absolve perceived suffering (typically of chronic health conditions) and where perpetrators kill in order to protect others in their care or for which they are responsible from perceived undue hardships (e.g., stress, financial burden, etc.). If not for confusion that might result, duty would be an apt name for this second sub-classification.

Murder-suicide as a subtype of suicide. One of the major arguments Joiner (2014) makes in his discussion of murder-suicide is that murder-suicide is, at its core, a type of suicide. Specifically cited are the similar rates of substance abuse and prevalence of mood disorders among murder-suicide and suicide perpetrators. The current study found suicide decedents to abuse substances at approximately twice the rate of murder-suicide perpetrators, though the difference was not statistically significant in the logistic regression. Suicide decedents were found to be much more likely to endorse current or prior mental health diagnoses or treatment. Depression was the most prevalent diagnosis for each group, but was endorsed far less frequently 
among murder-suicide perpetrators. Furthermore, suicide decedents were significantly more likely to disclose suicidal intent. Less than five percent of murder-suicide perpetrators had a recorded history of suicide attempts compared to nearly one-fifth of suicide decedents, a notable albeit not statistically significant difference. Murder-suicide perpetrators were far more likely to use a firearm and to enact interpersonal violence in the month prior to the fatal incident. These differences paint a picture of qualitative differences between suicide decedents and murdersuicide perpetrators. While some shared characteristics exist, murder-suicide perpetrators demonstrate less mental illness and less history of suicidality with more violence history and firearm use than suicide decedents. The data obtained in this study do not appear to be consistent with the conclusion that murder-suicide perpetrators are the same as suicide perpetrators with regard to psychological and incident variables. The prevailing current opinion of murder-suicide researchers is that murder-suicide perpetration occupies a domain distinct from, but overlapping with, both murder and suicide. The results of the current study are consistent with the conceptualization of murder-suicide as distinct from suicide, but sharing certain elements with suicide.

A clinical implication of these differences is that suicide prevention is not the same as murder-suicide prevention. While it is likely that suicide prevention strategies would be similarly effective at preventing murder-suicide, murder-suicide perpetrators are a population that is much less likely to come into contact with the routine suicide risk assessment and prevention strategies that exist in mental health systems. Because of their increased rate of committing interpersonal violence, murder-suicide perpetrators are more likely to come into contact with law enforcement systems. Implementation of suicide prevention strategies within a law enforcement context might 
prove to be a more successful arena for the prevention murder-suicide incidents than mental health contexts alone.

\section{Implications for Public Policy and Clinical Practice Interventions}

Targeted screening/assessment. While murder-suicide perpetrators are diverse and various idiographic factors affect each incident, general patterns of more common murdersuicide incidents types have emerged. For instance, males killing romantic partners during times of relationship volatility, depressed women killing children, and an elderly husband killing his ailing spouse are murder-suicide examples that represent something more than idiosyncratic events. When patterns of precipitating factors, demographic characteristics, psychological variables, and relationship variables become evident and are refined through emerging research on the most common classes of murder-suicide, we can begin to target assessments and interventions toward specific populations. The present study emphasized the examination of group factors that were considered dynamic and intervenable or amenable to intervention in addition to more static demographic and relational factors.

One such factor was recent interpersonal violence. While both males and female murdersuicide perpetrators evidenced high rates of recent interpersonal violence perpetration, males were more likely to kill for broader reasons of POV justice, and far more likely to kill for reasons of MTH amorous jealousy. Firearms are the most predominant weapon type used by males in general and individuals in the aforementioned POV and MTH motive categories. Romantic partners are the most frequent victims for these motive types. Using this known group information, targeted screening and logical interventions are possible. In an applied example, a male might present to a law enforcement and/or mental health agency for a recent problem with interpersonal violence. The circumstances of the violence would be assessed. If it were found 
that the male's violent acts were related to romantic relationship turmoil, he could be assessed for suicidality as well as homicidal ideation toward common targets in such incidents, his romantic partner and any suspected paramour. Interventions may include the assessment and potential temporary removal of lethal means, restraining orders or other measures to protect victims, and increased law enforcement monitoring and/or mental health contact. This is a rudimentary example, but the same logic can be applied to other individuals in circumstances where murder-suicides are most likely to occur.

Mothers suffering from depression are likely to be assessed for suicidality, but less likely to be assessed for homicidal ideation. Without assessing for homicidal ideation, a mother's statement that a child 'needs his mother' or 'would not fare well without her' may be seen as protective against suicide, evidence of responsibility and a reason for living. Now suppose the assessor was equipped with knowledge that a sizeable portion of perpetrators who kill for POV mercy and MTH altruistic/extended suicide reasons are females with mental health histories who kill their children. The individual conducting the assessment would clarify whether the mother sees her connection to her child as a protective reason for living or a worrisome extension of herself that may put the child at risk of death should the mother decide to complete murdersuicide. This and the former are but two illustrations of the potential clinical applications for data-informed screening procedures that have the potential to prevent murder-suicide.

Cognitive and therapeutic interventions. When individuals are identified as potential risks of murder-suicide, many of the same practices employed to manage suicide risk will also be effective ways to manage murder-suicide risk. Practical steps can be taken to manage risk including increased monitoring, safety planning, informing family members and/or legal entities of risk, arranging for removal of lethal means, referrals for mental health treatment (psychiatric 
medication; outpatient, day report, or inpatient treatments), and involuntary hospitalization (Fremouw, Tyner, Strunk, and Musick, 2005; Linehan, Comtois, and Ward-Ciesielski, 2012). Additional steps to warn or protect potential victims may be required depending on state laws and what is disclosed during the assessment.

The current study demonstrates that there are meaningfully different groupings of murder-suicide perpetrators by motive. From a clinical intervention perspective, one of the more helpful and advantageous parts of the perversion of virtue theory is the conceptualization of murder-suicide motives as perversions, or distortions, of typical beliefs. The cognitive piece in traditional cognitive behavioral therapies (CBT) has attempted to identify and modify what have been labeled irrational, maladaptive, and distorted beliefs. Mental health professionals could employ cognitive behavioral approaches to attempt to modify underlying beliefs that may contribute to an individual's consideration of murder-suicide. For instance, an individual may believe that after seeing her partner bedridden and scared by a recent cancer diagnosis the merciful thing to do would be to put him out of his misery - a distortion of the virtue, mercy. Through cognitive behavioral approaches involving challenges to or tests of her beliefs, this woman may come to find that her partner, while initially depressed and scared, has become appreciative of the abilities he still has left and has no wish to die. While this scenario is an oversimplification, it demonstrates that there are direct clinical implications that flow naturally from this conceptualization of murder-suicide. The potential for easily-identifiable translation from theory and research to clinical practice is a strength of the perversion of virtue theory.

Intervening with firearm policy. An overwhelming majority of murder-suicide incidents involve firearms. Firearms are a quick and highly lethal method that is used for both the murder and suicide portions of murder-suicides. There is existing evidence that intervening at 
the level of the lethal means can effectively reduce many, though certainly not all, murdersuicide incidents. Swanson, Bonnie, and Appelbaum (2015) state: "For suicide in the United States, the most important modifiable risk factor is access to firearms." The same can be said of murder-suicide as evidenced by decreased rates of murder-suicide in countries where firearms are not as readily available. There are many possible ways to approach reduction of murdersuicide through firearm policy interventions. Anestis and Anestis (2015) found that state laws requiring universal background checks, gun laws, and restricting open carrying of firearms were each associated with lower rates of suicide by firearm and suicide in general. At the individual level, there are certain circumstances (e.g., involuntary commitment, felony convictions) that make it illegal for individuals to own guns. Clinicians can ask clients and/or their families to voluntarily (and usually temporarily) remove lethal means. Clinicians can also educate clients about the potential risks of keeping firearms in the home, particularly unlocked and loaded firearms, when someone is in a vulnerable emotional state.

Some states are implementing innovative laws that allow for the temporary removal of firearms from persons deemed to be dangerous to themselves or others, even without mental illness (Swanson \& Felthous, 2015). Policies building off of this time-limited firearm removal are likely to be more palatable to individuals who feel that permanent restriction of firearms for at-risk individuals is encroaches on liberty in the name of safety. Given the data from the present study in which two thirds of murder-suicide perpetrators committed an act of interpersonal violence within one month of their fatal incident, there seems to be an avenue for reasonable and time-limited intervention to prevent murder-suicides. If known perpetrators of interpersonal violence had firearms temporarily removed from their possession for a brief time period (e.g., 60 days or 90 days) how many murder-suicides could be prevented? Skeptics will argue that 
individuals will find firearms through other means or will simply resort to other methods to enact murder-suicide. In some cases, these assertions are likely to be true. However, no weapon is as readily used or as lethal as a firearm already in possession of an individual intent on carrying out the two or more fatal acts involved in a murder-suicide.

Palliative care. The present study demonstrates that a class of murder-suicide perpetrators are motivated by reasons of perverted mercy or caring, usually of loved ones. A sizeable portion of these perpetrators kill close others to alleviate some perceived suffering stemming from medical conditions, injuries, and serious or terminal illness. The goal these perpetrators attempt to achieve is the same goal that professionals in palliative care have for an individual—reduction of suffering and pain. Palliative care also aims to increase functioning and improve the quality of an individual's life despite often severe medical conditions (Cherny, 2009). Yet, how many perpetrators were aware that palliative/supportive care was even an option for their loved one? While not discussed elsewhere, it is reasonable to ask whether public education interventions regarding the availability of supportive care measures, including hospice and comfort care, might be an effective alternative for this class of murder-suicide perpetrators. Knowing that a loved one will not be suffering can reduce distress among the potential murdersuicide perpetrator as well, potentially lessening motivation for both murder and suicide simultaneously.

Conclusions about clinical implications. There is no single motivation for murdersuicide and no single intervention strategy will prevent murder-suicides. Researchers, clinicians, and policy makers need to be creative and thoughtful when engineering solutions to this problem that claims over 1500 lives in the United States each year. Interventions for individuals enacting murder-suicide for mercy-motivated reasons are likely to differ in ways from those who do so for 
justice-related reasons. We cannot rely solely on interventions in the mental health domain, as many murder-suicide perpetrators are not coming into contact with mental health systems. They are coming into contact with law enforcement systems if interpersonal violence is involved, medical systems if severe illness is involved, legal systems if divorce and/or custody disputes are involved, and a plethora or other societal systems like unemployment offices or banks if job loss or financial strain hits. We know the common types of precipitating events and factors that are commonly associated with murder-suicide. We know that victims are usually among those closest to the perpetrators, and we know there are patterns of motives for why people enact murder-suicide. While further research is always needed, we know enough that we can be more intentional in our attempts to notice people who may be at risk of murder-suicide. We can begin to implement relevant policies, public education efforts, and mental health practices to reduce the occurrence of a devastating public health problem.

\section{Limitations and Future Research Directions}

Any conclusions drawn from the present study are only as good as the data provided. While the NVDRS is the most comprehensive database of murder-suicide incidents in the United States, it is not without flaws. The database is not yet nationally representative, and there is no quick way to find cases of murder-suicides. Homicide-only perpetrators are not sufficiently represented in the data to allow for comparisons with murder-suicide perpetrators. The majority of the data is categorical, thus restricting the range of possible statistical techniques. In this study, we relied heavily on the narrative data. The police and medical narratives were generally a rich data source, but there were instances in which no data were provided or there was not enough information to derive the age or relationship of individuals involved, let alone a motive. When narrative accounts were provided, they varied greatly with regard to length of narrative 
and specificity of information provided. Mental health diagnoses are infrequently reported among the data. Data on firearm ownership and acquisition was also missing. To advance the future of murder-suicide research with this database, the CDC could implement an easier way to locate cases of genuine murder-suicide, provide more information regarding mental health variables, and include more detailed and consistent narrative accounts of incidents.

The current dataset contains the largest known sample of female murder-suicide perpetrators and a matched sample of male perpetrators. While this sample selection was advantageous for the exploration of female versus male perpetrated murder-suicide, it is not a representative sample as it over represents female perpetrators. This means that the influence of female perpetrators is stronger than will be typically observed in a representative sample. Furthermore, it is worthwhile to note the inability of this study to measure or account for socialization with regard to gender and its impact on motive. While we studied groups arranged by biological sex, there is an undeniable interaction of sex and socially constructed gender that may contribute to the findings we describe as sex differences.

The definitions of murder-suicide motive types were carefully crafted to adhere to definitions set forth by the respective typologies' authors, but translating theoretical definitions into operational definitions is challenging. There is potential for distortion or misinterpretation in this process of operationally defining criteria for motives. Further, the NVDRS has been used to study murder-suicide in the past. Though different methods were used to select murder-suicide cases and the current study emphasized female perpetrators, it is likely that many of the cases cited in this study have been used in other NVDRS murder-suicide studies. Despite these limitations, we believe that the present study contributes in meaningful ways to the murdersuicide literature. First, we studied the largest known sample of female murder-suicide 
perpetrators, and are the first (to our knowledge) to operationally define and apply the perversion of virtue motives and test elements of this new murder-suicide theory.

Going forward, murder-suicide researchers are encouraged to make use of the richness of the NVDRS restricted access database - particularly as it moves toward becoming nationally representative. Researchers will likely also benefit from studying murder-suicide cases in more depth. Joiner (2014) suggests psychological autopsy as a potential avenue. Such studies are not novel, but amassing a large sample (in the hundreds) of murder-suicide psychological autopsies for investigation in a single study would be. The level of detailed information would greatly help to determine the presence of motive(s) and associated or precipitating factors. Another possible data source would be interviews with surviving perpetrators of murder-suicide attempts. Though there may be some systematic difference in completed versus non-completed murder-suicides, murder-suicide attempters may be able to provide valuable information with regard to motive, mental state at the time of the incident, and precipitating factors.

The current study demonstrates the importance of continuing to examine female murdersuicide perpetrators. While female perpetrators are rare, they are not the same as male perpetrators. If murder-suicide research continues to report only combined-sex data, then the unique qualities of female perpetrators will continue to be overlooked. A frequent problem with murder-suicide datasets is that there are not sizeable enough amounts of female perpetrators to conduct appropriately-powered statistical analyses. Possible remedies to this problem include tapping large databases and meta analyses of female perpetrators.

Future investigators could design, implement, and/or test the public policy and clinical interventions discussed here or develop and test their own. Murder-suicide rates could be examined in the years before and after implementing a systematic state-wide effort to educate 
patients and their families about palliative care as a health option. Researchers can assess the rate of murder-suicide in the years before and after states (or cities or countries) change firearm laws to become more or less restrictive. The effectiveness of programs encouraging medical, legal, and mental health staff to screen at-risk individuals for homicidal and suicidal ideation could be assessed.

With regard to the Joiner's (2014) perversion of virtue theory, the current study is an early attempt to operationally define, apply, and test parts of this novel theory. Our data challenge some assumptions (e.g., that murder-suicide falls within suicide; that the four motives are comprehensive) and support others (e.g., that mercy and justice are major and distinct motives). We hope that our research can contribute to the iterative process of refining a theory of this magnitude. Future research in this area might include revisions to our operational definitions, testing the theory with novel data, and finding a way to subdivide the larger mercy and justice classifications that is consistent with the theory. Subsequent tests of the theory are needed to corroborate or dispute our findings, with the ultimate goal of gaining a better understanding of murder-suicide. While it is unlikely that we will ever develop a comprehensive understanding or be able to prevent all murder-suicide, we can improve in both our understanding and our efforts to prevent these fatal events. 


\section{References}

Adinkrah, M. (2003). Homicide-suicides in Fiji: offense patterns, situational factors, and sociocultural contexts. Suicide \& Life-Threatening Behavior, 33(1), 65-73. Retrieved from http://www.ncbi.nlm.nih.gov/pubmed/12710541

Adinkrah, M. (2014). Homicide-suicide in Ghana: perpetrators, victims, and incidence characteristics. International Journal of Offender Therapy and Comparative Criminology, 58(3), 364-87. doi:10.1177/0306624X12470530

Allen, N. H. (1983). Homicide followed by suicide: Los Angeles, 1970-1979. Suicide and LifeThreatening Behavior, 13(3), 155-165.

Anestis, M. D., \& Anestis, J. C. (2015). Suicide rates and state laws regulating access and exposure to handguns. American Journal of Public Health, 105(10), 2049-2058.

Associated Press. (2015, June 22). Family of four shot dead in father's day murder-suicide. New York Post. Retrieved from http://nypost.com/2015/06/22/ family-of-four-shot-dead-in-fathers-day-murder-suicide/

Bossarte, R. M., Simon, T. R., \& Barker, L. (2006). Characteristics of homicide followed by suicide incidents in multiple states, 2003-04. Injury Prevention: Journal of the International Society for Child and Adolescent Injury Prevention, 12(Supplement 2), ii33-ii38. doi:10.1136/ip.2006.012807

Carcach, C., \& Grabosky, P. N. (1998). Murder-Suicide in Australia, (82). Australian Institute of Criminology. Retrieved from http://aic.gov.au/media_library/publications/tandi_pdf/ tandi082.pdf

Centers for Disease Control and Prevention. (2015, April 21). National violent death reporting 
system state profiles [Fact sheet]. Retrieved July 27, 2015, from Centers for Disease Control and Prevention website: http://www.cdc.gov/violenceprevention/ nvdrs/stateprofiles.html

Chan, C. Y., Beh, S. L., \& Broadhurst, R. G. (2003). Homicide-suicide in Hong Kong, 19891998. Forensic Science International, 137(2-3), 165-171. doi:10.1016/S03790738(03)00350-5

Cherny, N. I. (2009). Stigma associated with "palliative care". Cancer, 115(9), 1808-1812.

Cohen, D., Llorente, M., \& Eisdorfer, C. (1998). Homicide-suicide in older persons. The American Journal of Psychiatry, 155(3), 390-6. Retrieved from http://www.ncbi.nlm.nih.gov/pubmed/15728752

Cole, P. (1980). [Introduction]. In N. E. Breslow \& N. E. Day (Authors), Statistical methods in cancer research: The analysis of case-control studies (Vol. 1, pp. 14-40). Lyon, UK: International Agency for Research on Cancer.

Comstock, R. D., Mallonee, S., Kruger, E., Rayno, K., Vance, A., \& Jordan, F. (2005). Epidemiology of Homicide-Suicide Events: Oklahoma 1994-2001. The American Journal of Forensic Medicine and Pathology, 26(3), 229-235. doi:10.1097/01.paf.0000160681.40587.d3

Davies, H. T. O., Crombie, I. K., \& Tavakoli, M. (1998). When can odds ratios mislead? BMJ: British Medical Journal, 316(7136), 989. Retrieved from http://www.ncbi.nlm.nih.gov/pmc/articles/PMC1112884/

De Koning, E., \& Piette, M. H. (2014). A retrospective study of murder-suicide at the Forensic Institute of Ghent University, Belgium: 1935-2010. Medicine, Science, and the Law, 54(2), 88-98. doi:10.1177/0025802413518018 
Eliason, S. (2009). Murder-suicide: a review of the recent literature. The Journal of the American Academy of Psychiatry and the Law, 37(3), 371-6. Retrieved from http://www.ncbi.nlm.nih.gov/pubmed/19767502

Felthous, A. R., \& Hempel, A. (1995). Combined homicide-suicides: a review. Journal of Forensic Sciences, 40(5), 846-57. Retrieved from http://www.ncbi.nlm.nih.gov/pubmed/7595329

Fishbain, D. A., Rao, V. J., \& Aldrich, T. E. (1985). Female homicide-suicide perpetrators: a controlled study. Journal of Forensic Sciences, 30(4), 1148-56. doi: 10.1520/JFS11056J

Flynn, S., Swinson, N., While, D., Hunt, I. M., Roscoe, A., Rodway, C., ... \& Shaw, J. (2009). Homicide followed by suicide: a cross-sectional study. The Journal of Forensic Psychiatry \& Psychology, 20(2), 306-321.

Fremouw, W. J., Tyner, E. A., Strunk, J. M., \& Musick, R. (2005). Suicidal Adult Assessment protocol-SAAP. Washington, DC: American Psychological Association.

Google Scholar. (2015). Thomas Joiner. Retrieved July 27, 2015, from https://scholar.google.com/citations?user=x80a5W4AAAAJ\&hl=en

Hannah, S. G., Turf, E. E., \& Fierro, M. F. (1998). Murder-suicide in central Virginia: a descriptive epidemiologic study and empiric validation of the Hanzlick-Koponen typology. The American Journal of Forensic Medicine and Pathology, 19(3), 275-83. Retrieved from http://www.ncbi.nlm.nih.gov/pubmed/9760097

Hanzlick, R., \& Koponen, M. (1994). Murder-suicide in Fulton County, Georgia, 1988-1991: comparison with a recent report and proposed typology. The American Journal of Forensic Medicine and Pathology, 15(2), 168-173. doi: 10.1097/00000433-19940600000015 
Hongoltz-Hetling, M. (2015, July 8). Veterinarian victim of murder-suicide. Valley News. Retrieved from http://www.vnews.com/news/townbytown/lebanon/17670954-95/ veterinarian-victim-of-murder-suicide

Joiner, T. E. (2005). Why people die by suicide. Cambridge, Mass: Harvard University Press. Joiner, T. E. (2014). The perversion of virtue: Understanding murder-suicide. New York: Oxford University Press.

Karp, A. (2007, August). The largest civilian firearms arsenals for 178 countries [Chart]. Retrieved from http://www.smallarmssurvey.org/fileadmin/docs/A-Yearbook/2007/en/ Small-Arms-Survey-2007-Chapter-02-annexe-4-EN.pdf

Koziol-McLain, J., Webster, D., McFarlane, J., Block, C. R., Ulrich, Y., Glass, N., \& Campbell, J. C. (2006). Risk factors for femicide-suicide in abusive relationships: results from a multisite case control study. Violence and Victims, 21(1), 3-21. doi:10.1891/vivi.21.1.3

Krippendorff, K. (2008). Testing the reliability of content analysis data. In K. Krippendorff \& M. A. Bock (Eds.), The content analysis reader, 350-357. Thousand Oaks, CA: Sage.

Large, M., Smith, G., \& Nielssen, O. (2009). The epidemiology of homicide followed by suicide: a systematic and quantitative review. Suicide \& Life-Threatening Behavior, 39(3), 294306. doi:10.1521/suli.2009.39.3.294

Liem, M. (2010). Homicide followed by suicide: A review. Aggression and Violent Behavior, 15(3), 153-161. doi:10.1016/j.avb.2009.10.001

Liem, M., Barber, C., Markwalder, N., Killias, M., \& Nieuwbeerta, P. (2011). Homicide-suicide and other violent deaths: an international comparison. Forensic Science International, 207(1-3), 70-6. doi:10.1016/j.forsciint.2010.09.003 
Liem, M., \& Nieuwbeerta, P. (2010). Homicide followed by suicide: a comparison with homicide and suicide. Suicide \& Life-Threatening Behavior, 40(2), 133-45. doi:10.1521/suli.2010.40.2.133

Liem, M. C., \& Oberwittler, D. (2012). Homicide followed by suicide in Europe. In Handbook of European Homicide Research (pp. 197-215). Springer New York.

Liem, M., \& Roberts, D. W. (2009). Intimate partner homicide by presence or absence of a selfdestructive act. Homicide Studies, 13(4), 339-354. doi: 10.1177/1088767909347988

Linehan, M. M., Comtois, K. A., \& Ward-Ciesielski, E. F. (2012). Assessing and managing risk with suicidal individuals. Cognitive and Behavioral Practice,19(2), 218-232.

Logan, J. E., Hill, H. A., Black, M. L., Crosby, A. E., Karch, D. L., Barnes, J. D., \& Lubell, K. M. (2008). Characteristics of perpetrators in homicide-followed-by-suicide incidents: National Violent Death Reporting System--17 US States, 2003-2005. American Journal of Epidemiology, 168(9), 1056-64. doi:10.1093/aje/kwn213

Logan, J. E., Walsh, S., Patel, N., \& Hall, J. E. (2013). Homicide-followed-by-suicide incidents involving child victims. American Journal of Health Behavior, 37(4), 531-542. doi: 10.5993/AJHB.37.4.11

Malphurs, J. E., \& Cohen, D. (2002). A newspaper surveillance study of homicide-suicide in the United States. The American Journal of Forensic Medicine and Pathology, 23(2), 142-8. doi: 10.1097/00000433-200206000-00006

Manning, J. (2015). The Social Structure of Homicide-Suicide. Homicide Studies, 19(4), 350369. doi: $10.1177 / 1088767914547819$ 
Marzuk, P. M., Tardiff, K., \& Hirsch, C. S. (1992). The epidemiology of murder-suicide. JAMA: The Journal of the American Medical Association, 267(23), 3179-83. doi: 10.1001/jama.267.23.3179

McNally, M. R., Patton, C. L., \& Fremouw, W. J. (2015). Suicide (Behavior). In A Jamieson \& A.A. Moenssens (Eds.), Wiley Encyclopedia of Forensic Science. Chichester, England: Wiley. doi: 10.1002/9780470061589.fsa466.pub2.

McNally, M. R., Patton, C. L., \& Fremouw, W. J. (2016). Mining for murder-suicide: An approach to identifying cases of murder-suicide in the National Violent Death Reporting System (NVDRS) restricted access database (RAD). Journal of Forensic Sciences, 61(1), 245-248. doi: 10.1111/1556-4029.12887

Meyers, D. W. (2015, July 6). Officials: Two dead in Moxee apparent murder-suicide. Yakima Herald. Retrieved from http://www.yakimaherald.com/news/crime_and_courts/ officials-two-dead-in-moxee-apparent-murder-suicide/article_c659e946-23e1-11e5-84eeff4317d75b95.html

Miller, G. A. (1956). The magical number seven, plus or minus two: some limits on our capacity for processing information. Psychological Review, 63(2), 81-97. doi: 10.1037//0033295X.101.2.343

Milroy, C. M. (1995). The epidemiology of homicide-suicide (dyadic death). Forensic Science International, 71(2), 117-122. doi: 10.1016/0379-0738(94)01648-O

Milroy, C. M. (1998). Homicide followed by suicide: remorse or revenge? Journal of Clinical Forensic Medicine, 5(2), 61-4. doi: 10.1016/S1353-1131(98)90054-2

Nock, M. K., Borges, G., Bromet, E. J., Alonso, J., Angermeyer, M., Beautrais, A., ... \& Williams, D. (2008). Cross-national prevalence and risk factors for suicidal ideation, 
plans and attempts. The British Journal of Psychiatry, 192(2), 98-105. doi:

10.1192/bjp.bp.107.040113

Nock, M. K., \& Marzuk, P. M. (1999). Murder-suicide: Phenomenology and clinical implications. The Harvard Medical School guide to suicide assessment and intervention, 188-209.

Panczak, R., Geissbühler, M., Zwahlen, M., Killias, M., Tal, K., \& Egger, M. (2013). Homicidesuicides compared to homicides and suicides: systematic review and meta-analysis. Forensic Science International, 233(1-3), 28-36. doi:10.1016/j.forsciint.2013.08.017

Paulozzi, L.J., Mercy, J., Frazier, L., \& Annest, J. (2004). CDC's national violent death reporting system: background and methodology. Injury Prevention, 10(1), 47-52. doi:10.1136/ip.2003.003434

Peduzzi, P., Concato, J., Kemper, E., Holford, T. R., \& Feinstein, A. R. (1996). A simulation study of the number of events per variable in logistic regression analysis. Journal of Clinical Epidemiology, 49(12), 1373-1379. doi: 10.1016/S0895-4356(96)00236-3

Roberts, K., Wassenaar, D., Canetto, S. S., \& Pillay, A. (2010). Homicide-suicide in Durban, South Africa. Journal of Interpersonal Violence, 25(5), 877-99. doi:10.1177/0886260509336964

Salari, S., \& Sillito, C. L. (2016). Intimate partner homicide-suicide: Perpetrator primary intent across young, middle, and elder adult age categories. Aggression and Violent Behavior, 26, 26-34. doi: 10.1016/j.avb.2015.11.004

Saleva, O., Putkonen, H., Kiviruusu, O., \& Lönnqvist, J. (2007). Homicide-suicide—an event hard to prevent and separate from homicide or suicide. Forensic Science International, 166(2-3), 204-8. doi:10.1016/j.forsciint.2006.05.032 
Stack, S. (1997). Homicide Followed by Suicide: An analysis of Chicago Data. Criminology, 35(3), 435-453. doi:10.1111/j.1745-9125.1997.tb01224.x

Steenkamp, M., Frazier, L., Lipskiy, N., DeBerry, M., Thomas, S., Barker, L., \& Karch, D. (2006). The National Violent Death Reporting System: an exciting new tool for public health surveillance. Injury Prevention, 12(suppl 2), ii3-ii5. doi: 10.1136/ip.2006.012518

Swanson, J. W., Bonnie, R. J., \& Appelbaum, P. S. (2015). Getting serious about reducing gun violence: More "how" and less "why." Journal of the American Medical Association. Advance online publication. doi:10.1001/jama.2015.15566

Swanson, J. W., \& Felthous, A. R. (2015). Guns, mental illness, and the law: Introduction to this issue. Behavioral Sciences \& the Law, 22, 167-177. doi: 10.1002/bs1.2178

Van Orden, K. A., Witte, T. K., Cukrowicz, K. C., Braithwaite, S. R., Selby, E. A., \& Joiner, T. E. (2010). The Interpersonal Theory of Suicide.Psychological Review, 117(2), 575-600. doi:10.1037/a0018697

Violence Policy Center. (2012). American roulette: Murder-suicide in the United States, fourth edition. Retrieved from http://www.vpc.org/studies/amroul2012.pdf

Yip, P. S. F., Wong, P. W. C., Cheung, Y. T., Chan, K. S., \& Beh, S. L. (2009). An empirical study of characteristics and types of homicide-suicides in Hong Kong, 1989-2005. Journal of Affective Disorders, 112(1-3), 184-92. doi:10.1016/j.jad.2008.05.005 
Table 1

Interrater Reliability of Murder-Suicide Motive Codes as Measured by Krippendorff's Alpha (KALPHA)

\begin{tabular}{rccc}
\hline Motive Type & Number (n) & $\begin{array}{c}\text { Krippendorff's Alpha } \\
(\text { KALPHA) }\end{array}$ & $\begin{array}{c}\text { 95\% Confidence } \\
\text { Interval }^{\mathrm{b}}\end{array}$ \\
\hline All MTH Primary Motive & 270 & .63 & $.60-.66$ \\
$\begin{array}{r}\text { Amorous Jealousy } \\
\text { Declining Health }\end{array}$ & 64 & .71 & $.55-.87$ \\
$\begin{array}{r}\text { Altruistic/Extended Suicide } \\
\text { Family Financial/Social }\end{array}$ & 16 & .75 & $.56-.92$ \\
Stressors & 20 & .44 & $.10-.74$ \\
Retaliation & 78 & .69 & $.46-.91$ \\
All POV Primary Motive & & & $.41-.77$ \\
Mercy & 57 & .60 & $.58-.65$ \\
Justice & 146 & .61 & $.52-.86$ \\
Duty & 1 & .70 & $.60-.86$ \\
Glory & 0 & .73 & $-{ }^{\mathrm{a}}$ \\
$-{ }^{\mathrm{a}}$ & & & \\
\hline
\end{tabular}

Note. The $95 \%$ confidence intervals are based on 10000 bootstrap samples. Unknown and blended motives are not reported as separate motive codes, so all motive codes do not add up to 270.

${ }^{a}$ KALPHA levels and confidence intervals were not computed for these variables as they were seldom or never endorsed, Duty $(n=1)$, Glory $(n=0)$.

${ }^{b}$ Low reliability and large confidence intervals was influenced by both the low number of cases coded in some motives and the varying length and specificity of narrative data. 
Table 2

Demographic, Psychological, Incident, and Victim Variable Frequencies and Percentages for Male and Female Murder-Suicide Perpetrators.

\begin{tabular}{|c|c|c|}
\hline & $\begin{array}{l}\text { Male Perpetrators } \\
(\mathrm{N}=\mathbf{1 8 0})\end{array}$ & $\begin{array}{l}\text { Female Perpetrators } \\
(\mathrm{N}=90)\end{array}$ \\
\hline \multicolumn{3}{|l|}{ Perpetrator Variables } \\
\hline Age & $47.11(17.40)$ & $46.20(13.53)$ \\
\hline Ever Married & $133(73.9 \%)$ & $74(82.2 \%)$ \\
\hline White & $135(75.0 \%)$ & $70(77.8 \%)$ \\
\hline Non-Hispanic & $167(92.8 \%)$ & $83(92.2 \%)$ \\
\hline Drug or Alcohol Problem & $21(11.7 \%)$ & $7(7.8 \%)$ \\
\hline Any Mental Health & $21(11.7 \%)$ & $27(30.0 \%)$ \\
\hline \multicolumn{3}{|l|}{ History } \\
\hline Suicidal Intent & $22(12.2 \%)$ & $11(12.2 \%)$ \\
\hline Suicide Note & $35(19.4 \%)$ & $26(28.9 \%)$ \\
\hline History of Suicide & $5(2.8 \%)$ & $5(5.6 \%)$ \\
\hline \multicolumn{3}{|l|}{ Attempts } \\
\hline Victim of Interpersonal & $3(1.7 \%)$ & $0(0.0 \%)$ \\
\hline \multicolumn{3}{|l|}{$\begin{array}{r}\text { Violence } \\
\text { (Past month) }\end{array}$} \\
\hline Perpetrator of & $127(70.6 \%)$ & $54(60.0 \%)$ \\
\hline \multicolumn{3}{|l|}{$\begin{array}{r}\text { Interpersonal Violence } \\
\text { (Past month) }\end{array}$} \\
\hline Firearm & $163(90.6 \%)$ & $70(77.8 \%)$ \\
\hline \multicolumn{3}{|l|}{ Victim Variables } \\
\hline Age of Victim(s) & $43.41(19.37)$ & $32.79(24.18)$ \\
\hline Number of Victims & $1.22(0.75)$ & $1.20(0.43)$ \\
\hline Child Victim & $17(9.4 \%)$ & $44(48.9 \%)$ \\
\hline Romantic Partner Victim & $142(78.9 \%)$ & $39(43.3 \%)$ \\
\hline
\end{tabular}

Note. Means and standard deviations are reported for the 'age,' 'victim age,'and 'number of victims' variables, while all other variables contain frequency count and percentage. 
Table 3

Logistic Regression Model of Demographic, Psychological, Victim, and Incident Variables

Predicting Murder-Suicide Perpetrator Sex with Male as the Reference Group.

\begin{tabular}{|c|c|c|c|c|}
\hline Variable & $\boldsymbol{B}$ & $S E$ & OR & $95 \% \mathrm{CI}$ \\
\hline \multicolumn{5}{|l|}{ Perpetrator } \\
\hline Age & -.00 & .01 & 1.00 & {$[.98,1.02]$} \\
\hline Ever Married & -.13 & .43 & .88 & {$[.38,2.04]$} \\
\hline Drug or Alcohol Problem & .85 & .56 & 2.33 & {$[.77,7.07]$} \\
\hline Any Mental Health History & -1.15 & .44 & $.32 * *$ & {$[.14, .75]$} \\
\hline Suicidal Intent & .72 & .53 & 2.07 & {$[.73,5.90]$} \\
\hline Suicide Note & -.24 & .38 & .79 & {$[.37,1.67]$} \\
\hline History of Suicide Attempts & -.57 & .86 & 1.76 & {$[.33,9.50]$} \\
\hline Interpersonal Violence & .59 & .34 & 1.81 & {$[.94,3.49]$} \\
\hline \multicolumn{5}{|l|}{ Perpetration (Past month) } \\
\hline Firearm & .82 & .46 & 2.27 & {$[.91,5.63]$} \\
\hline \multicolumn{5}{|l|}{ Victim } \\
\hline Number of Victims & -1.71 & .51 & $.18 * *$ & {$[.07, .49]$} \\
\hline Child Victim & -2.95 & .60 & $.05^{* *}$ & {$[.02, .17]$} \\
\hline Romantic Partner Victim & .43 & .38 & 1.53 & {$[.73,3.23]$} \\
\hline
\end{tabular}

Note. $\mathrm{OR}=$ odds ratio; $\mathrm{CI}=$ confidence interval.

${ }^{*} p<.05$.

${ }^{* *} p<.01$. 
Table 4

Demographic, Psychological, Incident, and Victim Variable Frequencies and Percentages of Perversion of Virtue Murder-Suicide Motives.

\begin{tabular}{|c|c|c|c|}
\hline & $\begin{array}{c}\text { Mercy } \\
(\mathrm{n}=57)\end{array}$ & $\begin{array}{c}\text { Justice } \\
(\mathrm{n}=146)\end{array}$ & $\begin{array}{c}\text { Other }^{\mathrm{a}} \\
(\mathrm{n}=67)\end{array}$ \\
\hline \multicolumn{4}{|l|}{ Perpetrator Variables } \\
\hline Age & $59.91(17.51)$ & $43.03(12.69)$ & $43.88(16.31)$ \\
\hline Sex (Male) & $29(50.9 \%)$ & $111(76.0 \%)$ & $40(59.7 \%)$ \\
\hline Ever Married & $52(91.2 \%)$ & $109(74.7 \%)$ & $46(68.7 \%)$ \\
\hline White & $50(87.7 \%)$ & $107(73.3 \%)$ & $48(71.6 \%)$ \\
\hline Non-Hispanic & $54(94.7 \%)$ & $136(93.2 \%)$ & $60(89.6 \%)$ \\
\hline Drug or Alcohol Problem & $8(14.0 \%)$ & $17(11.6 \%)$ & $3(4.5 \%)$ \\
\hline Any Mental Health History & $12(21.1 \%)$ & $27(18.5 \%)$ & $9(13.4 \%)$ \\
\hline Suicidal Intent & $11(19.3 \%)$ & $15(10.3 \%)$ & $7(10.4 \%)$ \\
\hline Suicide Note & $26(45.6 \%)$ & $23(15.8 \%)$ & $12(17.9 \%)$ \\
\hline History of Suicide Attempts & $3(5.3 \%)$ & $3(2.1 \%)$ & $4(6.0 \%)$ \\
\hline $\begin{array}{r}\text { Victim of Interpersonal } \\
\text { Violence } \\
\text { (Past month) }\end{array}$ & $1(1.8 \%)$ & $2(1.4 \%)$ & $0(0.0 \%)$ \\
\hline $\begin{array}{r}\text { Perpetrator of Interpersonal } \\
\text { Violence } \\
\text { (Past month) }\end{array}$ & $34(59.6 \%)$ & $106(72.6 \%)$ & $41(61.2 \%)$ \\
\hline Firearm & $49(86.0 \%)$ & $131(89.7 \%)$ & $53(79.1 \%)$ \\
\hline \multicolumn{4}{|l|}{ Victim Variables } \\
\hline Age of Victim(s) & $51.69(26.74)$ & $37.71(17.89)$ & $35.30(21.28)$ \\
\hline Number of Victims & $1.21(.49)$ & $1.23(.76)$ & $1.18(.55)$ \\
\hline Child Victim & $20(35.1 \%)$ & $21(14.4 \%)$ & $20(29.9 \%)$ \\
\hline Romantic Partner Victim & $37(64.9 \%)$ & $107(73.3 \%)$ & $37(55.2 \%)$ \\
\hline
\end{tabular}

Note. Means and standard deviations are reported for the 'age,' 'victim age,'and 'number of victims' variables, while all other variables contain frequency count and percentage.

aCategory combines incidents coded as 'duty' $(\mathrm{n}=1)$, incidents with multiple motive categories, and incidents with unknown motives. 


\section{Table 5}

Logistic Regression Model of Demographic, Psychological, Victim, and Incident Variables

Predicting Murder-Suicide Perversion of Virtue Motives with Justice as the Reference Category.

\begin{tabular}{|c|c|c|c|c|}
\hline Variable & $\boldsymbol{B}$ & $S E$ & OR & $95 \% \mathrm{CI}$ \\
\hline \multicolumn{5}{|l|}{ Perpetrator } \\
\hline Age & -.11 & .02 & $.90 * *$ & {$[.86, .93]$} \\
\hline Sex (Male) & 1.27 & .49 & $3.58 * *$ & {$[1.38,9.27]$} \\
\hline Ever Married & -.56 & .68 & .57 & {$[.15,2.15]$} \\
\hline Drug or Alcohol Problem & .71 & .66 & 2.03 & {$[.56,7.34]$} \\
\hline Any Mental Health History & -.49 & .57 & .61 & {$[.20,1.89]$} \\
\hline Suicidal Intent & .69 & .58 & 1.99 & {$[.63,6.24]$} \\
\hline Suicide Note & 1.31 & .47 & $3.70 * *$ & {$[1.48,9.29]$} \\
\hline Interpersonal Violence & -.65 & .47 & .52 & {$[.21,1.30]$} \\
\hline Perpetration (Past month) & & & & \\
\hline \multicolumn{5}{|l|}{ Victim } \\
\hline Number of Victims & -.20 & .41 & .82 & {$[.36,1.84]$} \\
\hline Child Victim & 1.84 & .67 & $6.32 * *$ & {$[1.71,23.36]$} \\
\hline Romantic Partner Victim & .22 & .55 & 1.24 & {$[.42,3.66]$} \\
\hline
\end{tabular}

Note. $\mathrm{OR}=$ odds ratio; $\mathrm{CI}=$ confidence interval.

${ }^{*} p<.05$.

${ }^{* *} p<.01$. 
Table 6

Demographic, Psychological, Incident, and Victim Variable Frequencies and Percentages of Marzuk, Tardiff, and Hirsch Murder-

Suicide Motives.

\begin{tabular}{|c|c|c|c|c|c|c|}
\hline & $\begin{array}{l}\text { Amorous } \\
\text { Jealousy } \\
(n=64) \\
\end{array}$ & $\begin{array}{l}\text { Declining } \\
\text { Health } \\
(\mathbf{n}=\mathbf{3 1}) \\
\end{array}$ & $\begin{array}{l}\text { Altruistic } \\
\text { Extended } \\
\text { Suicide } \\
(\mathbf{n}=16) \\
\end{array}$ & $\begin{array}{c}\text { Family } \\
\text { Financial/Social } \\
\text { Stressors } \\
(\mathbf{n}=\mathbf{2 0})\end{array}$ & Retaliation & Other $^{\mathrm{a}}$ \\
\hline \multicolumn{7}{|l|}{ Perpetrator Variables } \\
\hline Age & $42.56(12.83)$ & $71.19(13.06)$ & $43.13(17.48)$ & $50.55(11.29)$ & $43.35(12.21)$ & $43.02(15.63)$ \\
\hline Sex (Male) & $53(82.8 \%)$ & $21(67.7 \%)$ & $3(18.8 \%)$ & $8(40.0 \%)$ & $54(69.2 \%)$ & $41(67.2 \%)$ \\
\hline Ever Married & $47(73.4 \%)$ & $28(90.3 \%)$ & $12(75.0 \%)$ & $20(100.0 \%)$ & $58(74.4 \%)$ & $42(68.9 \%)$ \\
\hline White & $47(73.4 \%)$ & $28(90.3 \%)$ & $14(87.5 \%)$ & $14(70.0 \%)$ & $59(75.6 \%)$ & $43(70.5 \%)$ \\
\hline Non-Hispanic & $61(95.3 \%)$ & $30(96.8 \%)$ & $14(87.5 \%)$ & $17(85.0 \%)$ & $72(92.3 \%)$ & $56(91.8 \%)$ \\
\hline Drug or Alcohol Problem & $6(9.4 \%)$ & $3(9.7 \%)$ & $3(18.8 \%)$ & $2(10.0 \%)$ & $11(14.1 \%)$ & $3(4.9 \%)$ \\
\hline Any Mental Health History & $7(10.9 \%)$ & $3(9.7 \%)$ & $7(43.8 \%)$ & $5(25.0 \%)$ & $19(24.4 \%)$ & $7(11.5 \%)$ \\
\hline Suicidal Intent & $10(15.6 \%)$ & $5(16.1 \%)$ & $5(31.3 \%)$ & $3(15.0 \%)$ & $5(6.4 \%)$ & $5(8.2 \%)$ \\
\hline Suicide Note & $11(17.2 \%)$ & $13(41.9 \%)$ & $10(62.5 \%)$ & $8(40.0 \%)$ & $10(12.8 \%)$ & $9(14.8 \%)$ \\
\hline History of Suicide Attempts & $3(4.7 \%)$ & $2(6.5 \%)$ & $1(6.3 \%)$ & $1(5.0 \%)$ & $1(1.3 \%)$ & $2(3.3 \%)$ \\
\hline Victim of IPV (Past month) & $0(0.0 \%)$ & $0(0.0 \%)$ & $0(0.0 \%)$ & $0(0.0 \%)$ & $2(2.6 \%)$ & $1(1.6 \%)$ \\
\hline IPV Perpetration (Past month) & $51(79.7 \%)$ & $18(58.1 \%)$ & $9(56.3 \%)$ & $10(50.0 \%)$ & $55(70.5 \%)$ & $38(62.3 \%)$ \\
\hline Firearm & $61(95.3 \%)$ & $28(83.9 \%)$ & $12(75.0 \%)$ & $16(80.0 \%)$ & $67(85.9 \%)$ & $51(83.6 \%)$ \\
\hline \multicolumn{7}{|l|}{ Victim Variables } \\
\hline Age of Victim(s) & $39.10(14.32)$ & $68.71(15.79)$ & $24.99(22.58)$ & $37.40(23.10)$ & $35.97(20.64)$ & $36.07(19.74)$ \\
\hline Number of Victims & $1.16(.72)$ & $1.03(.18)$ & $1.31(.60)$ & $1.40(.60)$ & $1.29(.82)$ & $1.18(.53)$ \\
\hline Child Victim & $2(3.1 \%)$ & $3(9.7 \%)$ & $11(68.8 \%)$ & $10(50.0 \%)$ & $20(25.6 \%)$ & $15(24.6 \% 0$ \\
\hline Romantic Partner Victim & $57(89.1 \%)$ & $24(77.4 \%)$ & $7(43.8 \%)$ & $11(55.0 \%)$ & $46(59.0 \%)$ & $36(59.0 \%)$ \\
\hline
\end{tabular}

Note. Means and standard deviations are reported for the 'age,' 'victim age,'and 'number of victims' variables, while all other variables contain frequency count and percentage. IPV = Interpersonal Violence

${ }^{a}$ Category combines multiple motive categories and unknown motives. 
Table 7

Multinomial Logistic Regression Model of Demographic, Psychological, Victim, and Incident Variables Predicting Murder-Suicide Marzuk, Tardiff and Hirsch Motives with Retaliation as the

Reference Category.

\begin{tabular}{|c|c|c|c|c|}
\hline Variable & $\boldsymbol{B}$ & $S E$ & OR & $95 \% \mathrm{CI}$ \\
\hline \multicolumn{5}{|l|}{ Retaliation v. Amorous Jealousy } \\
\hline \multicolumn{5}{|l|}{ Perpetrator } \\
\hline Age & -.01 & .02 & 1.00 & {$[.96,1.03]$} \\
\hline Sex (Male) & -.08 & .51 & .93 & {$[.34,2.50]$} \\
\hline Ever Married & -.24 & .50 & .79 & {$[.30,2.07]$} \\
\hline Drug or Alcohol Problem & .33 & .63 & 1.39 & {$[.41,4.72]$} \\
\hline Any Mental Health History & 1.14 & .65 & 3.13 & {$[.89,11.08]$} \\
\hline Suicidal Intent & -2.50 & .82 & .08 & {$[.02, .40]$} \\
\hline Suicide Note & -.82 & .59 & .44 & {$[.14,1.39]$} \\
\hline History of Suicide Attempt & -3.42 & 1.62 & $.03 *$ & {$[.00, .77]$} \\
\hline Interpersonal Violence & -.57 & .48 & .57 & {$[.22,1.46]$} \\
\hline \multicolumn{5}{|l|}{ Perpetration (Past month) } \\
\hline Firearm & -1.74 & .85 & .18 & {$[.03, .93]$} \\
\hline \multicolumn{5}{|l|}{ Victim } \\
\hline Number of Victims & .30 & .28 & 1.35 & {$[.78,2.33]$} \\
\hline Child Victim & 2.806 & .95 & $16.55 * *$ & {$[2.55,107.25]$} \\
\hline Romantic Partner Victim & -1.29 & .55 & $.28 *$ & {$[.10, .81]$} \\
\hline \multicolumn{5}{|l|}{ Retaliation v. Declining Health } \\
\hline \multicolumn{5}{|l|}{ Perpetrator } \\
\hline Age & .19 & .04 & $1.21 * *$ & {$[1.12,1.31]$} \\
\hline Sex (Male) & -.81 & .78 & .45 & {$[.10,2.07]$} \\
\hline Ever Married & 1.89 & 1.02 & 6.61 & {$[.89,48.88]$} \\
\hline Drug or Alcohol Problem & -.35 & 1.17 & .71 & {$[.07,6.94]$} \\
\hline Any Mental Health History & .35 & .97 & 1.42 & {$[.21,9.53]$} \\
\hline Suicidal Intent & -2.06 & 1.05 & $.13 *$ & {$[.02, .99]$} \\
\hline Suicide Note & -1.60 & .79 & $.20 *$ & {$[.04, .95]$} \\
\hline History of Suicide Attempt & -3.21 & 1.81 & .04 & {$[.00,1.39]$} \\
\hline Interpersonal Violence & 1.37 & .76 & 3.92 & {$[.88,17.48]$} \\
\hline Perpetration (Past month) & & & & \\
\hline Firearm & .07 & 1.10 & 1.07 & {$[.13,9.17]$} \\
\hline \multicolumn{5}{|l|}{ Victim } \\
\hline Number of Victims & -1.20 & 1.99 & .30 & {$[.01,14.97]$} \\
\hline Child Victim & 1.59 & 1.25 & 4.92 & {$[.43,56.81]$} \\
\hline Romantic Partner Victim & .11 & .92 & 1.11 & {$[.18,6.76]$} \\
\hline
\end{tabular}




\begin{tabular}{|c|c|c|c|c|}
\hline Variable & $\boldsymbol{B}$ & $S E$ & $\mathbf{O R}$ & $95 \% \mathrm{CI}$ \\
\hline \multicolumn{5}{|l|}{$\begin{array}{l}\text { Retaliation v. } \\
\text { Altruistic/Extended Suicide } \\
\text { Perpetrator }\end{array}$} \\
\hline Age & .01 & .03 & 1.01 & {$[.95,1.08]$} \\
\hline Sex (Male) & -2.27 & .90 & $.10 *$ & {$[.02, .60]$} \\
\hline Ever Married & .47 & .96 & 1.60 & {$[.24,10.50]$} \\
\hline Drug or Alcohol Problem & -.22 & .98 & .80 & {$[.12,5.44]$} \\
\hline Any Mental Health History & -.02 & .79 & .98 & {$[.21,4.58]$} \\
\hline Suicidal Intent & -1.51 & .90 & .22 & {$[.04,1.30]$} \\
\hline Suicide Note & -2.67 & .77 & $.07 * *$ & {$[.02, .31]$} \\
\hline History of Suicide Attempt & -1.20 & 1.68 & .30 & {$[.01,8.17]$} \\
\hline Interpersonal Violence & 1.21 & .73 & 3.37 & {$[.81,14.00]$} \\
\hline Perpetration (Past month) & & & & \\
\hline Firearm & -.71 & .89 & .49 & {$[.09,2.81]$} \\
\hline \multicolumn{5}{|l|}{ Victim } \\
\hline Number of Victims & -.60 & .81 & .55 & {$[.11,2.69]$} \\
\hline Child Victim & -1.40 & 1.21 & .25 & {$[.02,2.64]$} \\
\hline Romantic Partner Victim & -1.00 & 1.06 & .37 & {$[.05,2.92]$} \\
\hline \multirow{2}{*}{\multicolumn{5}{|c|}{$\begin{array}{l}\text { Retaliation v. Family } \\
\text { Financial/Social Stressors } \\
\text { Perpetrator }\end{array}$}} \\
\hline & & & & \\
\hline Age & .04 & .03 & 1.04 & {$[.99,1.09]$} \\
\hline Sex (Male) & -1.21 & .67 & .30 & {$[.08,1.12]$} \\
\hline Ever Married $^{\mathrm{a}}$ & -- & -- & -- & -- \\
\hline Drug or Alcohol Problem & .85 & .97 & 2.34 & {$[.35,15.69]$} \\
\hline Any Mental Health History & 1.24 & .84 & 3.47 & {$[.68,17.82$} \\
\hline Suicidal Intent & -1.36 & .96 & .26 & {$[.04,1.68]$} \\
\hline Suicide Note & -1.84 & .70 & $.16^{* *}$ & {$[.04, .63]$} \\
\hline History of Suicide Attempt & -2.27 & 1.64 & .10 & {$[.00,2.57]$} \\
\hline Interpersonal Violence & 1.56 & .64 & $4.74 * *$ & {$[1.35,16.60]$} \\
\hline Perpetration (Past month) & & & & \\
\hline Firearm & .17 & .77 & 1.18 & {$[.26,5.39]$} \\
\hline \multicolumn{5}{|l|}{ Victim } \\
\hline Number of Victims & .76 & .64 & 2.14 & {$[.61,7.52]$} \\
\hline Child Victim & -.50 & .88 & .61 & {$[.11,3.41]$} \\
\hline Romantic Partner Victim & -.91 & .76 & .40 & {$[.09,1.81]$} \\
\hline
\end{tabular}

Note. $\mathrm{OR}=$ odds ratio; $\mathrm{CI}=$ confidence interval.

${ }^{\text {a}}$ EverMarried is not reported in this case, because all cases of Family Financial Stressors have been previously married (quasi complete separation)

$* \mathrm{p}<.05$.

$* * \mathrm{p}<.01$. 
Table 8

Multinomial Logistic Regression Model of Demographic, Psychological, Victim, and Incident Variables Predicting Murder-Suicide Marzuk, Tardiff and Hirsch Motives with

Altruistic/Extended Suicide as the Reference Category.

\begin{tabular}{|c|c|c|c|c|}
\hline Variable & $\boldsymbol{B}$ & $S E$ & OR & $95 \% \mathrm{CI}$ \\
\hline \multicolumn{5}{|l|}{$\begin{array}{l}\text { Altruistic/Extended Suicide v. } \\
\text { Amorous Jealousy } \\
\text { Perpetrator }\end{array}$} \\
\hline Age & -.02 & .03 & .98 & {$[.92,1.05]$} \\
\hline Sex (Male) & 2.20 & .92 & $8.98 * *$ & {$[1.49,54.22]$} \\
\hline Ever Married & -.71 & 1.02 & .49 & {$[.07,3.63]$} \\
\hline Drug or Alcohol Problem & .55 & 1.04 & 1.73 & {$[.23,13.21]$} \\
\hline Any Mental Health History & 1.17 & .91 & 3.21 & {$[.54,19.22]$} \\
\hline Suicidal Intent & -1.00 & .96 & .37 & {$[.06,2.41]$} \\
\hline Suicide Note & 1.85 & .82 & $6.36^{*}$ & {$[1.27,31.74]$} \\
\hline History of Suicide Attempt & -2.22 & 1.91 & .11 & {$[.00,4.55]$} \\
\hline Interpersonal Violence & -1.78 & .79 & $.17 *$ & {$[.04, .79\}$} \\
\hline Perpetration (Past month) & & & & \\
\hline Firearm & -1.04 & 1.13 & .36 & {$[.04,3.22]$} \\
\hline \multicolumn{5}{|l|}{ Victim } \\
\hline Number of Victims & .89 & .84 & 2.44 & {$[.47,12.65]$} \\
\hline Child Victim & 4.21 & 1.44 & $67.15^{* *}$ & {$[3.97,1137.12]$} \\
\hline Romantic Partner Victim & -.28 & 1,13 & .75 & {$[.08,6.91]$} \\
\hline \multicolumn{5}{|l|}{$\begin{array}{l}\text { Altruistic/Extended Suicide v. } \\
\text { Declining Health } \\
\text { Perpetrator }\end{array}$} \\
\hline Age & .18 & .05 & $1.20 * *$ & {$[1.09,1.31]$} \\
\hline Sex (Male) & 1.47 & 1.10 & 4.33 & {$[.50,37.54]$} \\
\hline Ever Married & 1.42 & 1.32 & 4.15 & {$[.31,54.85]$} \\
\hline Drug or Alcohol Problem & -.13 & 1.41 & .88 & {$[.05,13.94]$} \\
\hline Any Mental Health History & .37 & 1.14 & 1.45 & {$[.15,13.67]$} \\
\hline Suicidal Intent & -.56 & 1.13 & .57 & {$[.06,5.21]$} \\
\hline Suicide Note & 1.07 & .94 & 2.93 & {$[.47,18.38]$} \\
\hline History of Suicide Attempt & -2.02 & 1.87 & .13 & {$[.00,5.24]$} \\
\hline Interpersonal Violence & .15 & .94 & 1.17 & {$[.19,7.33]$} \\
\hline Perpetration (Past month) & & & & \\
\hline Firearm & .77 & 1.27 & 2.17 & {$[.18,26.09]$} \\
\hline \multicolumn{5}{|l|}{ Victim } \\
\hline Number of Victims & -.60 & 2.12 & .55 & {$[.01,34.74]$} \\
\hline Child Victim & 3.00 & 1.58 & 19.98 & {$[.91,438.31]$} \\
\hline Romantic Partner Victim & 1.11 & 1.31 & 3.03 & {$[.23,39.26]$} \\
\hline
\end{tabular}




\begin{tabular}{|c|c|c|c|c|}
\hline Variable & $\boldsymbol{B}$ & $S E$ & OR & $95 \% \mathrm{CI}$ \\
\hline \multicolumn{5}{|l|}{$\begin{array}{l}\text { Altruistic/Extended Suicide v. } \\
\text { Family Financial/Social } \\
\text { Stressors } \\
\text { Perpetrator }\end{array}$} \\
\hline Age & .03 & .04 & 1.03 & {$[.96,1.10]$} \\
\hline Sex (Male) & 1.07 & .99 & 2.90 & {$[.42,20.24]$} \\
\hline Ever Married $^{\mathrm{a}}$ & -- & -- & -- & -- \\
\hline Drug or Alcohol Problem & 1.07 & 1.18 & 2.91 & {$[.29,29.55]$} \\
\hline Any Mental Health History & 1.27 & .97 & 3.55 & {$[.53,23.92]$} \\
\hline Suicidal Intent & .14 & 1.03 & 1.15 & {$[.15,8.64]$} \\
\hline Suicide Note & .83 & .84 & 2.30 & {$[.45,11.87]$} \\
\hline History of Suicide Attempt & -1.07 & 1.79 & .34 & {$[.01,11.36]$} \\
\hline Interpersonal Violence & .34 & .82 & 1.41 & {$[.28,6.97]$} \\
\hline Perpetration (Past month) & & & & \\
\hline Firearm & .87 & .98 & 2.39 & {$[.35,16.28]$} \\
\hline \multicolumn{5}{|l|}{ Victim } \\
\hline Number of Victims & 1.36 & .91 & 3.88 & {$[.65,23.22]$} \\
\hline Child Victim & .90 & 1.31 & 2.46 & {$[.19,31.82]$} \\
\hline Romantic Partner Victim & .10 & 1.15 & 1.10 & {$[.11,10.55]$} \\
\hline
\end{tabular}

Note. $\mathrm{OR}=$ odds ratio; $\mathrm{CI}=$ confidence interval. Altruistic/Extended Suicide v. Retaliation is not included in the table because the comparison was included in Table 12.

${ }^{a}$ EverMarried is not reported in this case, because all cases of Family Financial Stressors have been previously married (quasi complete separation)

$* \mathrm{p}<.05$.

$* * \mathrm{p}<.01$. 
Table 9

Crosstabulation of Marzuk, Tardiff, and Hirsch (MTH) and Perversion of Virtue (POV) Primary Motive Codes for 270 Murdersuicide Incidents.

\begin{tabular}{|c|c|c|c|c|c|c|c|}
\hline \multirow[b]{2}{*}{ MTH Motives } & \multicolumn{6}{|c|}{ POV Motives } & \multirow[b]{2}{*}{ Total } \\
\hline & Mercy & Justice & Duty & Glory & $\begin{array}{l}\text { Blended } \\
\text { Undifferentiated }\end{array}$ & Unknown & \\
\hline Amorous Jealousy & 0 & 62 & 0 & 0 & 0 & 2 & 64 \\
\hline Declining Health & 27 & 0 & 1 & 0 & 0 & 3 & 31 \\
\hline Altruistic/ Extended Suicide & 10 & 2 & 0 & 0 & 1 & 3 & 16 \\
\hline Family Financial/ Social Stressors & 15 & 3 & 0 & 0 & 0 & 2 & 20 \\
\hline Retaliation & 1 & 69 & 0 & 0 & 1 & 7 & 78 \\
\hline Blended Undifferentiated & 4 & 4 & 0 & 0 & 0 & 0 & 8 \\
\hline Unknown & 0 & 6 & 0 & 0 & 0 & 47 & 53 \\
\hline Total & 57 & 146 & 1 & 0 & 2 & 64 & 270 \\
\hline
\end{tabular}


Table 10

Demographic, Psychological, and Incident Variable Frequencies ${ }^{\mathrm{a}}$ and Logistic Regression Model Predicting Incident Type.

\begin{tabular}{|c|c|c|c|c|c|c|}
\hline \multirow[b]{2}{*}{ Variable } & \multicolumn{2}{|c|}{ Incident Type } & \multirow[b]{2}{*}{$\boldsymbol{B}$} & \multirow[b]{2}{*}{$S E$} & \multirow[b]{2}{*}{ OR } & \multirow[b]{2}{*}{$95 \% \mathrm{CI}$} \\
\hline & $\begin{array}{l}\text { Suicide } \\
(\mathbf{N}=\mathbf{3 6 0})\end{array}$ & $\begin{array}{l}\text { Murder-Suicide } \\
(\mathrm{N}=\mathbf{2 7 0})\end{array}$ & & & & \\
\hline Age & $45.68(17.63)^{\mathrm{a}}$ & $46.80(16.19)^{\mathrm{a}}$ & -.01 & .01 & .99 & {$[.98,1.01]$} \\
\hline Ever Married & $246(68.3 \%)$ & $207(76.7 \%)$ & .57 & .32 & 1.77 & {$[.94,3.31]$} \\
\hline White & $329(91.4 \%)$ & $205(75.9 \%)$ & -.71 & .37 & .49 & {$[.24,1.01]$} \\
\hline Non-Hispanic & $348(96.7 \%)$ & $250(92.6 \%)$ & -1.28 & .59 & $.28^{*}$ & {$[.09, .88]$} \\
\hline $\begin{array}{l}\text { Drug or Alcohol } \\
\text { Problem }\end{array}$ & $79(21.9 \%)$ & $28(10.4 \%)$ & -.21 & .34 & .81 & {$[.41,1.59]$} \\
\hline $\begin{array}{l}\text { Any Mental } \\
\text { Health History }\end{array}$ & $174(48.3 \%)$ & $48(17.8 \%)$ & -1.05 & .30 & $.35^{* *}$ & {$[.19, .63]$} \\
\hline Suicidal Intent & $105(29.2 \%)$ & $33(12.2 \%)$ & -.69 & .33 & $.50^{*}$ & {$[.26, .96]$} \\
\hline Suicide Note & $99(27.5 \%)$ & $61(22.6 \%)$ & -.24 & .29 & .79 & {$[.45,1.37]$} \\
\hline $\begin{array}{l}\text { History of Suicide } \\
\text { Attempts }\end{array}$ & $67(18.6 \%)$ & $10(3.7 \%)$ & -.26 & .49 & .77 & {$[.29,2.03]$} \\
\hline $\begin{array}{l}\text { Interpersonal } \\
\text { Violence Victim } \\
\text { (Past month) }\end{array}$ & $2(0.6 \%)$ & $3(1.1 \%)$ & -.27 & 2.34 & .76 & {$[.01,74.8]$} \\
\hline $\begin{array}{l}\text { Interpersonal } \\
\text { Violence Perp. } \\
\text { (Past month) }\end{array}$ & $9(2.5 \%)$ & $181(67.0 \%)$ & 4.23 & .40 & $68.58^{* *}$ & $\begin{array}{l}{[31.25,} \\
150.47]\end{array}$ \\
\hline Firearm & $170(47.2 \%)$ & $233(86.3 \%)$ & 1.70 & .31 & $5.46^{* *}$ & $\begin{array}{l}{[2.98} \\
10.01]\end{array}$ \\
\hline
\end{tabular}

Note. $\mathrm{OR}=$ odds ratio; $\mathrm{CI}=$ confidence interval.

${ }^{\mathrm{a}}$ Means and standard deviations are reported for age.

* $p<.05$.

** $p<.01$. 
Appendix A

\section{Examples of National Violent Death Reporting System (NVDRS) Law Enforcement and}

\section{Medical Narrative Accounts of Murder Suicide Incidents}

Narrative accounts provide varying levels of specificity and detail. Examples include:

- CME not available.

- $\quad$ SHR: V: 37 yo bm; S: 38 yo bm; weapon: handgun; relationship: husband

- V1 was a black male who shot a black female (V2) and then shot himself. V1 called the police to confess prior to his suicide. Nothing further is known.

- According to PR: wf died of blunt force injuries to the head with a baseball bat at residence inflicted by husband (V/S-wm) who then shot himself in the head with a .357caliber revolver at residence. $\mathrm{V}$ and $\mathrm{V} / \mathrm{S}$ were in court earlier the day of the incident for arbitration over the residence as they were going through a divorce. No further details.

- V (unknown age Black male) was apparently shot by his wife B (unknown age Black female), who then shot herself. B was being treated for chronic pain as well as depression and had a past history of psychiatric stays in a hospital. $\mathrm{V}$ and $\mathrm{B}$ were known to have had marital problems in the past and had divorced, then remarried several years later.

- V1, a 46 year old male, shot V2 (V1's mother), a 66 year old white female, at their residence. Afterwards, V1 shot himself in the chest. No suicide note found. Both V's were pronounced at scene. V1 had been arguing with V2 before shooting her. V1 had been consuming alcohol prior to death. V2 had not been consuming alcohol prior to death. Both V's tested negative for drug usage. V1 was supposed to be seeking psychiatric help. V1 died of a self-inflicted gsw to the chest. V1's manner of death is suicide. V2 died of two shotgun wounds to the torso. V2's manner of death is homicide.

- 20 y/o Hispanic female V was shot and killed by 40 y/o White male S/V (V's XBF). V was at her workplace when $\mathrm{S} / \mathrm{V}$ entered the business and shot her multiple times with a .357 caliber revolver. S/V then shot himself in the head. One bullet passed through the wall into the business next door and grazed an employee there in the shoulder. EMS at scene found S/V still alive and he was transported to hospital where he died 3 days later. Reportedly V and S/V had lived together for an unknown time. V had broken up with $\mathrm{S} / \mathrm{V}$ and he was not taking it well. $\mathrm{V}$ had moved in with her mother a few weeks prior to this event and was still getting phone calls from $\mathrm{S} / \mathrm{V}$. V had been advised by police to seek a restraining order against $\mathrm{S} / \mathrm{V}$. Search of $\mathrm{S} / \mathrm{V}$ 's clothing revealed two suicide notes that included a DNR order. It was learned S/V was $\$ 20,000$ behind in child support for his $11 \mathrm{y} / \mathrm{o}$ son by his $\mathrm{x}$-wife. According to $\mathrm{x}$-wife she and S/V had married due to her becoming pregnant and the marriage quickly ended. S/V had hx of somewhat dysfunctional relationship with women. 
Appendix B

\title{
Perversion of Virtue (POV) Typology of Murder-Suicide Coding Definitions
}

\author{
$\underline{\text { Important Points }}$
}

- The following motive definitions refer to the motive a perpetrator has for the murder $(s)$ as part of a given murder-suicide incident.

- All information needed to conclude motive is to be derived from narrative police and/or medical examiner reports as part of the NVDRS RAD.

- The goal is to allow for the coding of all narratives that are sufficiently detailed as to allow the derivation of motive based on clear and accurate coding rules.

- The definitions are written in such a manner as to allow for the coding of one primary motive, but may also be used to allow for the coding of presence/absence of each of the four major motives

\section{Coding Instructions}

1. Please fully read all narrative reports of the incident.

2. Reading coding definitions to determine whether four motives (mercy, justice, duty, glory) are present in the narrative according to coding rules

a. Code ' 1 ' in the column for 'present' or ' 0 ' for 'absent' for each motive

3. Determine which motive is primary and mark the appropriate number in the 'primary motive' column.

a. A primary motive is one that is most supported by the narrative.

b. While multiple motives may be present, primacy is determined by attempting to answer the question 'why did this perpetrator murder this (these) victim(s)?'

c. Temporal closeness of motive-linked events to murder should be considered when determining primacy (e.g., bankruptcy 3 days prior to a father perpetrated murdersuicide carries more weight than the victim son's verbal altercation with father one year ago) 


\section{Mercy $=1$}

Broad Definition: Evidence of killing others to prevent real or perceived suffering of the victim upon the perpetrator's death.

Evidence of the Mercy type of murder-suicide can be found in narratives that mention:

- At least one of A or B

- At least one of $\mathrm{C}$ or $\mathrm{D}$

A) Killing of an individual with a chronic, terminal, or painful illness

- Illnesses identified in the narrative can be reasonably assumed to be known by perpetrator (unless explicitly stated that the perpetrator did not know)

$\mathrm{AND} / \mathrm{OR}$

B) Killing of children, family, (and often pets) who would likely otherwise be unable to care for themselves (and may suffer without the perpetrator)

- Such perceived suffering of victims upon perpetrator's death may include physical suffering, severe mental/emotional anguish, financial/economic suffering (such as bankruptcy or homelessness), or shame/embarrassment (due to perpetrator or victim's legal charges or other forms of public shame)

- Real suffering upon perpetrators death is reasonably likely or there is explicit evidence (e.g., written/verbal or collateral report) that perpetrator believed victims would suffer upon perpetrator's death

AND

C) Killing is done without evidence of Duty (ensuring that responsibilities do not fall to or burden another surviving individual), Justice, or Glory as primary motive, and does not include behavioral evidence of grossly/obviously unmerciful means of death (e.g., narrative report concluding evidence of torture, intentional prolonging of suffering, beheading, dismemberment, or disembowelment, etc.)

OR

D) Narrative report includes explicit mention of Mercy (e.g., alleviation of suffering as described above) via written or verbal report of perpetrator or as noted by report of other individual in narrative report of incident.

\section{Examples include:}

- Killing of an individual with terminal illness

- Killing of children (and pets) who would otherwise be unable to care for themselves (if perpetrator perceives suffering) 


\section{$\underline{\text { Justice }=2}$}

Broad Definition: Evidence of retaliation or vengeance, killing to correct a perceived slight, wrong, or injustice.

Evidence of the Justice type can be found in narratives that mention:

- At least one of A or B

$\circ \mathrm{C}$ is present

A) Killing an individual involved in real or perceived injustice, slight, or wrong toward the perpetrator

- Killing current, former, or perceived spouse or romantic partner (and may also include the spouse/romantic partner's real or perceived paramour)

$\circ$ Killing individual with whom the perpetrator was involved in a current or historical dispute or disagreement (e.g., argument, fight, land/property dispute, being fired/reprimanded, romantic dispute, custody dispute, lawsuit, criminal accusations, threats, domestic violence, etc.)

\section{$\mathrm{AND} / \mathrm{OR}$}

B) Killing individual(s) close to those who have caused real or perceived injustice, slight, or wrong toward the perpetrator

- Killing the real or perceived paramour of a current, former, or perceived spouse or romantic partner

- Killing of children or other close family/friends (and potentially pets) to spite an ex-spouse/partner and/or to induce suffering in the survivor (as indicated by written or verbal report of perpetrator or as noted by report of other individual in narrative report of incident)

- Killing of close family/friends (and potentially pets) to spite an individual and induce suffering (as indicated by written or verbal report of perpetrator or as noted by report of other individual in narrative report of incident)

- Killing (known or unknown) individuals of or representative of a group that has caused real or perceived injustice/slight/wrong toward the perpetrator

AND

C) Motive is not better classified as primarily Mercy, Duty, or Glory (see definitions)

\section{Examples include:}

○ killing romantic partner following relationship termination and/or killing romantic partner's paramour

○ killing children to spite ex-spouse

$\circ$ killing former boss after being fired

$\circ$ killing another as a result of a fight or argument 
○ killing individuals from a group (e.g., church, women, government) because of perceived wrong/injustice/slight committed by that group 


\section{$\underline{\text { Duty }=3}$}

Broad Definition: Evidence of killing to ensure that the perpetrator's (human) responsibilities do not fall onto another surviving individual

Evidence of the Duty type can be found in narratives that mention:

$\circ$ All of A, B, and C

A) Killing of an individual (and potentially pets) for whom the perpetrator is in some way responsible (e.g., caretaking financial, housing, medical, or legal responsibility)

- If unable to be definitively derived from narrative, one can reasonably assume perpetrator responsibility for victim based on perpetrator-victim relationship (e.g., family, cohabitant, etc.) or employment/role (e.g., home health aide, power of attorney, etc.)

AND

B) Murder is to alleviate responsibility that would fall to another individual upon perpetrator's death based on explicit evidence of duty from narrative report:

- written or verbal communication regarding duty motive for murder

○ behavioral evidence of Duty (e.g., leaving out will, life insurance, etc., or other similar efforts to lessen burden on surviving individuals)

o other mention of Duty in narrative report (e.g., police, medical examiner, or family)

AND

C) Killing is done without primary evidence of Mercy (killing to alleviate suffering by the victim), Justice, or Glory

\section{Examples include:}

- Caretaker killing disabled adult friend so caretaking responsibilities do not fall to other surviving children

- Mother killing child and stating in a note that she did so to prevent others from having to raise her child

- Male kills family following job loss/bankruptcy and left voicemail telling friend that he could not burden others by asking them to provide support with housing or finances 


\section{Glory $=4$}

Broad Definition: Evidence of killing for post-mortem notoriety

Evidence of the Glory type can be found in narratives that mention:

$\circ$ Both $\mathrm{A}$ and $\mathrm{B}$ are present

A) Explicit evidence (e.g., perpetrator verbal/written report, or other individual report in narrative) that the perpetrator killed other(s) primarily for purposes of attempting achieving post-mortem notoriety/significance (e.g., media attention or other public recognition of significance), to be noticed, set a record, be remembered as significant, or die for a specific cause

- Behaviorally, killing of two or more individuals (when motive is not better explained by Duty, Mercy, or Justice - Criterion B) is sufficient for deriving a probable motive of Glory

AND

B) Primary motive is not better explained by Duty, Mercy, or Justice (see definitions)

\section{Examples include:}

- Public spree killings, school shootings, killings of well-known public figures, and (potentially) acts of terrorism. 


\section{Blended (Multiple) $=5$}

Broad Definition: Multiple motives (mercy, justice, duty, glory) are identified as being present, but primacy cannot be assigned to a single motive.

\section{Evidence of Blended-Multiple type can be found in narratives that mention:}

○ Incidents in which there is sufficient evidence for multiple primary motives (e.g., full evidence for two or more primary murder motives - most commonly in a multiple victim murder-suicide incident - for example, one killing for justice and another for mercy).

Note in comments column the blended motive type: [ex: 2 (Justice), 3 (Duty)]

\section{Blended (Undifferentiated) $=6$}

Broad Definition: Multiple motives (mercy, justice, duty, glory) are identified as being present, but primacy cannot be assigned to a single motive due to lack of differentiation among motives

Evidence of Blended-Undifferentiated type can be found in narratives that contain:

A) Enough information to rule out some motives, but not enough information to reliably conclude a single primary motive (e.g., can reduce to duty/mercy or justice/glory).

Note in comments column the blended motive type: [ex: 1 (Mercy), 3 (Duty)] 


\section{Other $=7$}

Broad Definition: A motive is known, but that motive that cannot be assigned to any of the prior motives (mercy, justice, duty, glory)

Evidence of the Other type can be found in narratives that mention:

$\circ$ Both A and B

A) Information is present in the narrative to draw a conclusion regarding motive

B) One or a combination of the prior motives cannot be identified as the primary motive using coding rules

Examples Include:

$\circ$ There is another identifiable motive that does not fit/ is not captured by the four primary motives

Note in comments column the other motive type.

\section{$\underline{\text { Unknown }=9}$}

Broad Definition: A motive cannot be reasonably derived from the information provided

Evidence of the Unknown type can be found in narratives that mention:

A) A lack of substantive evidence that would allow for the derivation of a motive

- Dearth of information does not allow for motive types to be reasonably ruled out or assigned

\section{Examples include:}

○ "Two males (one suspect, one victim) found dead of gunshot wounds in public park. Circumstances and relationship unknown."

- "A man was found dead of a self-inflicted gunshot wound, an unknown female was found in the next room with a gunshot wound from the deceased male. Relationship unknown, no other information provided."

Note: Even the addition of a simple phrase such as "Neighbors/Passersby heard/observed the individuals arguing loudly prior to hearing gunshots" would allow for a coder to reasonably conclude a motive of Justice in either case. 


\section{Coding Summary Sheet}

1.) Code the presence or absence of the following motives for murder in separate columns, where $1=$ present and $0=$ absent:
Mercy
Justice
Duty
Glory

2.) Code the primary motive for murder, in the primary motive column:

$$
\begin{aligned}
& 1=\text { Mercy } \\
& 2=\text { Justice } \\
& 3=\text { Duty } \\
& 4=\text { Glory } \\
& 5=\text { Blended (Multiple) } * \\
& 6=\text { Blended (Undifferentiated) } * \\
& 7=\text { Other } * \\
& 9=\text { Unknown }
\end{aligned}
$$

*requires comment in the comment column 
Appendix C

\section{Marzuk, Tardiff, and Hirsch (MTH) Murder-Suicide Coding Definitions}

\section{$\underline{\text { Important Points }}$}

- The following motive definitions refer to the motive a perpetrator has for the murder(s) as part of a given murder-suicide incident.

- All information needed to conclude motive is to be derived from narrative police and/or medical examiner reports as part of the NVDRS RAD.

- The goal is to allow for the coding of all narratives that are sufficiently detailed as to allow the derivation of motive based on clear and accurate coding rules.

- The definitions are written in such a manner as to allow for the coding of one primary motive, but may also be used to allow for the coding of presence/absence of each of the five major motives

\section{Coding Instructions}

1. Please fully read all narrative reports of the incident.

2. Reading coding definitions to determine whether for motives (amorous jealousy, declining health, altruistic/extended, family financial/social stressor, retaliation) are present in the narrative according to coding rules

a. Code ' 1 ' in the column for 'present' or '0' for 'absent' for each motive

3. Determine which motive is primary and mark the appropriate number in the 'primary motive' column.

a. A primary motive is one that is most supported by the narrative.

b. While multiple motives may be present, primacy is determined by attempting to answer the question 'why did this perpetrator murder this (these) victim(s)?'

c. Temporal closeness of motive-linked events to murder should be considered when determining primacy (e.g., bankruptcy 3 days prior to a father perpetrated murdersuicide carries more weight than the victim son's verbal altercation with father one year ago) 


\section{$\underline{\text { Amorous Jealousy }=1 \text { (Relationship Dissolution) }}$}

Broad Definition: Evidence of killing a current or former, real or perceived romantic partner (and/or a paramour) due to relationship dissolution (real, perceived, pending, historical, or threatened)

\section{Evidence of the Amorous Jealousy type of murder-suicide can be found in narratives that mention:}

- Both A and B

A) If the victim and the perpetrator ever had a real or perceived romantic relationship and there is clear evidence of relationship dissolution (real, pending, perceived, threatened, or historical)

- Jealousy/anger relating to romantic partner (current, former, or perceived)

- Infidelity (real or perceived); Lover's triangle

- Any other evidence of dissolution, separation, etc.

AND

B) Act is perpetrated against either or both of the following:

$\circ{ }^{1}$ the real/perceived/historical romantic partner

- Spouse, dating partner, or mutual romantic partner, etc.

$\circ{ }^{2}$ the real/perceived/historical romantic rival or paramour

- Ex-wife's boyfriend (real or suspected); husband's former mistress or girlfriend; girlfriend's other boyfriend, etc.

NOTES: Code as the primary motive only if there is evidence indicating $\mathrm{real} /$ perceived/threatened/historical dissolution of relationship as primary and proximal motive. Examples of this include:

$\circ$ A current restraining order among individuals in a relationship is evidence of current relationship dissolution

- History of intimate partner violence or domestic violence alone is NOT sufficient

- A domestic violence history alone is not evidence of relationship dissolution

$\circ$ Evidence of past relationship alone is not evidence that the primary motive is relationship dissolution (as opposed to anger/frustration or depression)

Key words/themes: jealousy, divorce, break-up, ex-boyfriend/girlfriend, ex-husband/wife, infidelity

\section{Examples Include:}

$\circ$ Boyfriend shoots long-term girlfriend and then himself. Family of the deceased girlfriend report she had recently told them she was going to leave her boyfriend. 
- Male was shot and killed by his girlfriend's ex-boyfriend, who shot and killed himself. The two males were reportedly engaged in an altercation at the home of the girlfriend and were heard arguing about her. 


\section{$\underline{\text { Declining Health Type }=2}$}

Definition: Motive for murder-suicide is to end the physical suffering of a loved one (parent, child, romantic partner, etc.) or to end one's own physical suffering

Evidence of the Declining Health type of murder-suicide can be found in narratives that mention:

- Both A and B

A) Physical suffering of perpetrator and/or loved one exists

- Diagnosed medical condition, often chronic/fatal

- Not a delusion

- Often includes associated depression

AND

B) Must have evidence that perpetrator committed act as a result of health conditions

- Critical element: "but for" failing health of the suspect or victim, the murder-suicide would NOT occur as evidenced by:

- Notes, statements, or conclusions of medical examiner/law enforcement.

- Without this element, consider other codes

Key words/themes: disease, chronic illness, poor health, ending suffering

\section{Case Examples:}

- Male removes wife's required oxygen and then shoots self on the driveway. A note he left indicates that his wife's condition had gotten worse and he was not going to let her suffer.

- Wife shot in the head by husband. Husband then shot himself in the head. The wife was known to have Parkinson's disease and spinal stenosis. On the day of the incident, the husband left a message on his friend's voicemail, indicating that he has suffered a stroke and couldn't move his left arm, and mentioned pre-planned funeral arrangements. The husband also left a note addressed to this friend at his residence." 


\section{$\underline{\text { Altruistic/Extended Suicide }=\mathbf{3}}$}

Definition: Motive for murder-suicide is to help victim escape from continued (non-health) hardships or hardships upon the perpetrator's death

Evidence of the Altruistic/Extended type of murder-suicide can be found in narratives that mention:

- Both A and B

A) Killing based on an altruistic belief that doing so prevents victim from enduring continued (non-health) hardships

- Altruism may include the killing of individuals in the perpetrator's care, based on the belief that "there would be no one to care for the [individual]" -Nock and Marzuk (1999)

- Evidence that the perpetrator feels he or she is "altruistically delivering [victim(s)] from continued hardships" may be found in:

- Suicide notes, communications, etc. indicating that world is bad, dangerous, place

- Documentation of "Salvation fantasies of rescue or escape from problems"

- May include depression with psychotic features

○ Conclusions of altruism/extended suicide present in the narrative

AND

B) Primary motive is not better explained by amorous jealousy, declining health, financial/social stressors, or retaliation motives

- Victims are often individuals the perpetrator wants to take with him/her for altruistic, but not retaliatory reasons

- Death of victim is not a primarily result of physical illness or suffering by the perpetrator or victim

NOTES: Perpetrators who kill victims in their care (e.g., children, elders, individuals with disabilities) are coded this type, absent other more proximal motives

Associated Features (not required, but often present):

- Victims are often viewed as extensions of the perpetrator

- Evidence of depression/hopelessness/despair - recent diagnosis, treatment or statements indicating depression/hopelessness/despair

- External life stressors are often present (frequently recent)

- In the absence of clear evidence of altruistic motive, these cases are coded as " 4 = family financial/social stressors" 
Key words/themes: Perpetrator often depressed/suicidal/hopeless, recent life stressors, victims are close to the individual — often seen as an extension of the self (partner, children, family, pets), extended suicide

\section{Examples Include:}

- Mother kills children after deciding to attempt suicide.

- Male kills wife, children, and pets while depressed/intoxicated 


\section{$\underline{\text { Family Financial/Social Stressor }=4}$}

Broad Definition: Evidence of killing close others (typically family) due to financial or social stressors affecting the family

Evidence of the Family Financial/Social Stressors type of murder-suicide can be found in narratives that mention:

○ $\mathrm{A}$ is present

A) Killing close others (typically family) with evidence of family financial or social stressors

- Financial or social stressors are often relatively recent (typically within the past few weeks or months)

- Examples of stressors include real or threatened loss of job or home; bankruptcy; legal charges

- Perpetrator may feel as though he/she is delivering loved ones from continued financial or social hardship relating to the above-listed examples-similar to altruistic type, but proximal precipitating factors are family financial or social stressors

- Often displays evidence of depression or paranoia

NOTES

- When coding primary motive: it is not better explained by retaliation, amorous jealousy, declining health, or altruism

Key words/themes: Money, financial stress, bankruptcy, indicted, legal problems, legal charges, arrest, job loss, home loss, home foreclosure, bad investment

Examples Include:

- Man kills wife and child because he is under severe financial pressure and facing home foreclosure. No other motives present/known. 


\section{$\underline{\text { Retaliation }=5 \text { (Conflict) }}$}

Broad Definition: Evidence of killing due to conflict between individuals not directly relating to the dissolution of a romantic relationship

Evidence of the Retaliation type of murder-suicide can be found in narratives that mention:

- A is present

A) Killing is motivated by a conflict between individuals not directly relating to the dissolution of a romantic relationship.

- Precipitating factors: feeling slighted, humiliated, angry, frustrated, vengeful, or spiteful

- Conflict/Altercation may be regarding subjects such as:

- Disrespect (real or perceived humiliation/rejection); Blocking a goal;

Money/Job/Housing/Pets/Children; Annoyance/Frustration

\section{NOTES:}

- Arguments resulting in murder-suicide between romantic partners are coded here, unless there is evidence that the argument is more proximally related to dissolution of relationship, altruistic motives, or family financial/social stressors

- Evidence of recent domestic violence (within past 2 weeks) may constitute nonromantic conflict (if it is unrelated to dissolution of relationship)

- Individuals who kill children or relatives to spite romantic partner during or after relationship dissolution are coded here

- Individuals who kill strangers or acquaintances for real or perceived motives such as disrespect, goal blocking, etc. are coded here.

○ Include mass killings, spree killings where surmised motive includes perceived wronging or disrespect

Key words/themes: Conflict, altercation, dispute, argument, fight, disrespect, family, relative, spite, upset, frustration, being slighted, humiliated

\section{Examples include:}

- "Female (22yo) shoots her mother (53yo) during an argument and then shoots herself."

- Male shot his ex-girlfriend. The man then shot himself in the head after he returned to his residence. The man and his girlfriend had been arguing at the man's home when the ex-girlfriend was shot." 


\section{Blended (Multiple) $=6$}

Broad Definition: Multiple motives (amorous jealousy, declining health, altruistic/extended, family financial/social stressor, retaliation) are identified as being present, but primacy cannot be assigned to a single motive.

\section{Evidence of Blended-Multiple type can be found in narratives that mention:}

- Incidents in which there is sufficient evidence for multiple primary motives (e.g., full evidence for two or more primary murder motives - most commonly in a multiple victim murder-suicide incident - for example, one killing for justice and another for mercy).

Note in comments column the blended motive type: [ex: 4 (family financial/social stressor), 5 (Retaliation)]

\section{Blended (Undifferentiated) $=7$}

Broad Definition: Multiple motives (amorous jealousy, declining health, altruistic/extended, family financial/social stressor, retaliation) are identified as being present, but primacy cannot be assigned to a single motive due to lack of differentiation among motives

\section{Evidence of Blended-Undifferentiated type can be found in narratives that contain:}

- Enough information to rule out some motives, but not enough information to reliably conclude a single primary motive (e.g., can reduce to 2 motives).

Note in comments column the blended motive type: [ex: 1 (amorous jealousy), 3 (family financial/social stressor)] 


\section{$\underline{\text { Other }=8}$}

Broad Definition: A motive is known, but that motive that cannot be assigned to any of the prior motives (mercy, justice, duty, glory)

Evidence of the Other type can be found in narratives that mention:

○ Both $\mathrm{A}$ and $\mathrm{B}$

C) Information is present in the narrative to draw a conclusion regarding motive

D) One or a combination of the prior motives cannot be identified as the primary motive using coding rules

Key words/themes: There is another identifiable motive that does not fit/ is not captured by the five major motive types

Note in comments column the other motive type.

\section{$\underline{\text { Unknown }=9}$}

Broad Definition: A motive cannot be reasonably derived from the information provided

\section{Evidence of the Unknown type can be found in narratives that mention:}

- A lack of substantive evidence that would allow for the derivation of a motive

- Dearth of information does not allow for motive types to be reasonably ruled out or assigned

- Motive is unknown - cannot be reliably surmised from given information

- Ex: Man and woman found dead, he shot her then self, relationship and circumstances unknown

Key words/themes: Not enough information, no circumstances known

\section{Examples include:}

○ "Two males (one suspect, one victim) found dead of gunshot wounds in public park. Circumstances and relationship unknown."

- "A man was found dead of a self-inflicted gunshot wound, an unknown female was found in the next room with a gunshot wound from the deceased male. Relationship unknown, no other information provided." 


\section{Coding Summary Sheet}

1.) Code the presence or absence of the following motives for murder in separate columns, where $1=$ present and $0=$ absent:

Amorous Jealousy

Declining Health

Altruistic/Extended Suicide

Family financial/social stressors

Retaliation

2.) Code the primary motive for murder, in the primary motive column:

$$
\begin{aligned}
& 1=\text { Amorous Jealousy } \\
& 2=\text { Declining Health } \\
& 3=\text { Altruistic/Extended Suicide } \\
& 4=\text { Family financial/social stressors } \\
& 5=\text { Retaliation } \\
& 6=\text { Blended (Multiple) } * \\
& 7=\text { Blended (Undifferentiated) } * \\
& 8=\text { Other } \\
& 9=\text { Unknown }
\end{aligned}
$$

*requires comment in the comment column 
Appendix D

\section{Coding Rules for Merging Three Raters' Motive Codes into One Code}

$\underline{\text { Present/Absent Codes ( } 1=\text { Present; } 0=\text { Absent })}$

1.) If two or more raters code a motive as present ( $\operatorname{code}=1)$, then it is coded as present ( code $=1)$.

2.) When two or more raters code a motive as absent (code $=0$ ), then it is coded as absent

$\underline{\text { Primary Motive }}$

1.) When two or more coders agree on a primary motive, it is coded as the primary motive.

2.) When none of the coders agree on a primary motive

a. Any motive endorsed as "present" by two or more coders is primary

i. If multiple motives are endorsed as present by two or more coders with no agreement in primary motive, the code with most number of endorsements is primary

1. If no primary agreement and equal endorsement of two or more motives by two or more coders, then the primary motive is considered 'blended (undifferentiated)'

b. If no motive is endorsed as present by two or more coders, then the primary motive is considered 'unknown' 